\title{
¿Hemos de renunciar a Hegel? \\ Debate sobre la vigencia del proyecto hegeliano *
}

\author{
ROMANO GARCIA $\dagger$ \\ Universidad de Extremadura \\ «Hegel no negó el porvenir. Ningún porvenir rencgará de Hegel.» \\ E. Bloch ${ }^{1}$
}

Nadie duda de las dificultades que siente todo estudioso de Hegel: dificultades de interpretación y -no digamos- de adhesión. También existe gran unanimidad en reconocer que Hegel es irrefutable cuando es confrontado desde dentro del sistema: y así, Tugendhat propone criticarlo desde fuera, con la ayuda de Heidegger, Mead y Wittgenstein - como veremos más adelante- Asumimos, at exponerlas, tales dificultades -que implican, en el sentir de algunos, la necesidad de erenunciar a Hegel» ${ }^{2}$, condición para que adquieran una mínima fuerza los argumentos de una posible reivindicación del proyecto hegeliano.

I. Iniciamos el debate afrontando los argumentos esgrimidos para renunciar a Hegel.

A. Uno de los más fuertes se relaciona con la llamada abolición de la namatividad ${ }^{3}$.

La filosofía de la historia es fundamental en el pensamiento hegeliano. Pero la historia que estudia Hegel no es la del historiador, sino ta del filósofo: historia del proceso de realización de la libertad, que es tarea de la razón. La Enciclopedia describe, de manera completa, tal proceso de racionalización y liberación. Y los Principios de la filosofía del Derecho exponen ese proceso en el campo social y político. En tal sentido, el sistema hegeliano descansa en esta afirmación: «La razón rige el mundo $y$, por tanto, la historia universal ha transcurrido racionalmente. Esta convicción y evidencia es un supuesto con respecto a la historia como tal. En la filosofia empero no es un supuesto. En ella está demostrado, mediante el pensamiento especulativo, que la razón es la sustancia ${ }^{4}(L F H \mathrm{I}, 20 ; W 12,20)$. La filosofia hegeliana de la historia, como explica Collingwood, «no es una reflexión filosófica sobre la historia, sino la historia misma elevada a una potencia superior y vuelta filosófica en cuanto distinta de la meramente empírica, es decir, historia no meramente comprobada como hechos, sino comprendida por aprehensión de las razones por las que acontecieron los hechos como acontecicron ${ }^{5}$. Esa comprensión de la historia hizo decir a Hannah Arendt que Hegel fue «el primer gran pensador que consideró seriamente a la historias ${ }^{6}$.

El Nons de Anaxágoras, la Providencia cristiana y la teodicea de Leibniz palidecen ante la razón gobernadora del mundo, inmanente a él. Leamos otra vez a Hegel: «[La razón es] potencia infinita, porque la razón no es tan impotente que sólo alcance al ideal, a lo que debe ser, y sólo cxista fuera de la realidad, quién sabe dónde, qui-

\footnotetext{
* El Profesor Rumano García falleció el 28 de marzo de 1998, después de haber entregado estc trabajo que Isegoria publica ahora en homenaje a su memoria.
} 
zá como algo particular en las cabezas de algunos hombres». Y, por otro lado, «la razón, por ser potencia infinita, no ha menester, como la acción finita, condiciones de un material externo; no necesita de medios dados, de los cuales reciba el sustento, los objetos de su actividad; se alimenta de sí misma y es ella misma el material que elabora" ( $L F H ~ 1,20 ; W 12,21)$. «Tal credo filosófico - comenta Ricoeur- refuta, en la Fenomenología y en la Enciclopedia, de manera obstinada, la escisión entre un formalismo de la idea y un empirismo del hechow?

Además, el proceso histórico significa la unificación del espíritu subjetivo y el espiritu objetivo en el cspiritu absoluto, proceso que no es más que la vuelta del espíritu a sí mismo: en tal proceso no parece haber lugar para la contingencia y la novedad. He aqui las afirmaciones con las que Hegel cierra la Introducción general de las Lecciones sobre la filosofia de la historia universal: $« \mathrm{El}$ espíritu fue siempre lo que es ahora... El espíritu sigue teniendo en sí todas las fases del pasado... Siempre nos ocupamos del presente cuando recorremos el pasado... El espíritu sigue teniendo, en su fondo actual, los momentos que parece tener detrás de sín ( $L F H \mathrm{I}, 150$; $W 12,105)$.

Esta comprensión de la historia ha provocado muy duras objeciones - tras ser valorada, es cierto, en su grandiosidadpor parte de algunos de los más ilustres estudiosos de Hegel: Gadamer, Ricoeur, Tugendhat, Habermas, por citar sólo aquellos de los que nos haremos eco con algún detenimiento.

1. Gadamer, en uno de los más brillantes capítulos de su Verdad y método, relaciona este proyecto de Hegel con el proyecto de la hermenéutica. En efecto. La hermenéutica afronta el problema de la relación del presente con la tradición - con el pasado-: en tal sentido, «la exigencia de la hermenéutica sólo parece satisfacerse en la infinitud del saber, de la mediación pensante de la totalidad de la tradición con el presente». La hermenéutica se basa en «el ideal de una llustración total [acabada], de la ruptura [abolición] total de los límites de nuestro horizonte histórico, de la superación de la propia [nuestra] finitud en la infinitud del saber, en una palabra, en la omnipresencia del espíritu que sabe históricamente» ${ }^{8}$. $\mathrm{Ni}$ Schleiermacher, ni Von Humboldt han llegado a ver las exigencias que este proyecto conlleva: «Es la involucración panteista de toda individualidad en lo absoluto lo que hace posible el milagro de la comprensión; también aquí el ser y el saber se interpenetran mutuamente en lo absoluto" ${ }^{9}$. Fue Hegel quien advirtió las exigencias del planteamiento: «Hegel pensó hasta el final [extremo] la dimensión histórica en la que tiene sus raíces el problema de la hermenéutica... Por eso, la confrontación con él es tan importante para el problema hermenéutico. La filosofía del espíritu de Hegel pretende lograr una mediación total de historia y presente" ${ }^{10}$. Gadamer se pregunta: « ¿ No nos obliga esto a dar [la] razón a Hegel? ¿No tendremos que admitir como fundamento de la hermenéutica la mediación absoluta de [entre] historia y verdad tal como la pensaba Hegel?» "11. La respuesta de Gadamer es tajante: no.

Gadamer no refuta a Hegel: reconoce «su supcrioridad frente a todos sus críticos» ${ }^{12}$; aducir contradicciones, apelar a críticas hechas desde sus presupuestos resulta estéril. Pero el proyecto es inviable. Gadamer aduce que nuestra conciencia histórica implica la conciencia de la situación: «El concepto de situación se caracteriza por que uno no sc encuentra frente a ella y, por tanto, no puede tener un saber objetivo de ella. Se está en ella, uno se encuentra siempre en una situación cuya iluminación es una tarea a la que nunca se puede dar cumplimiento por entero... Pero esta inacababilidad no es defecto de la reflexión, sino que está en la esencia 
misma del ser histórico que somos. Ser histórico quiere decir no agotarse nunca en el saberse... El concepto de la situación se determina justamente en que representa una posición que limita las posibilidades de ver. Al concepto de la situación le pertenccc csencialmente el concepto de horizonte» ${ }^{13}$. Falla el presupuesto que sostiene al sistema hegeliano: «la mediación absoluta de lentre] historia y verdads ${ }^{14}$.

2. También Ricoeur se aparta de Hegel en este punto, señalando que, con ello, su posición es próxima a la de Gadamer ${ }^{15}$. En el capítulo «Renunciar a Hegel» de Temps et récit, dedica un apartado a «La imposible mediación total»: «La finitud de la interpretación [autocomprensión de la conciencia histórica] significa que todo pensamiento pensante posee sus presupucstos que no domina»; la interpretación puede ser afectada por acontecimientos que le desbordan: el intento de Hegel es tambićn «un fenómeno hermenéutico, una operación interpretante, sometida a la misma condición de finitud». El proyecto hegeliano, aunque constituye una tentación, resulta inviable. Renunciar a Hegel significa srenunciar a descifrar la trama suprema». Pero aplicar al mismo Hegel la condición finita de la autocomprensión de la conciencia histórica «no constituye un argumento contra Hegel; significa que nosotros no pensamos según Hegel, sino después de Hegel» ${ }^{16}$.

3. Por otro lado, el progreso de la libertad - su efectuación- coincide con el retorno del Espíritu a sí mismo, constituye, realmente, una autopresencia. La filosofía ve la vida de lo absoluto sin temporización real: "La identidad entre la explicitación y el retomo a si es el presente eterno» ${ }^{17}$. La consecuencia es inevitable: "Lsta adecuación de la efectividad y de la presencia marca la abolición de la namativa en la consideración pensante de la historias ${ }^{18}$.

La historia es evolución y la evolución es - nos recuerda Zubiri- obra de la «razón dialécticamente constituida»; pero «todas las grandes creaciones de la historia están para $\mathrm{Hcgcl}$ prcincluidas en el germen del que dialécticamente salen; en este sentido, no se produce en la historia nada radicals ${ }^{19}$. Queda, así, abolida la historia: el progreso es un regreso, el desarrollo es un retorno.

La renuncia es dolorosa en proporción a la grandiosidad de lo que se abandona: «Porque ¿qué lector, una vez que ha sido seducido, como nosotros, por la potencia de su pensamiento, no sentirá el abandono de Hegel como una herida, que, a diferencia precisamente de las heridas del Espíritu absoluto, no acaba curándose? $\%$.

B. El otro argumento se relaciona con la abolición de la subjetividad y conciencia individtuales.

1. Ricoeur, al renunciar a Hegel, pone también el énfasis en otro punto: la absorción de la conciencia individual por la institución, la comunidad y el Estado. Hegel ha expresado claramente su visión de este problema con el tema de astucia de la razón. El espíritu del mundo se anexiona, en el espíritu del pueblo, como instrumento de sus designios, los intereses de los individuos: en éstos —en sus voluntadesexisten objetivos determinados y finitos que conocen y otros que les sobrepasan y que pueden desconocer; esto último da lugar a que la acción individual produzca efectos no queridos y que poseen su lógica propia: «Las vidas de los individuos, al buscar y satisfacer sus propios fines, son a la vez el medio y el instrumento de algo superior y más amplio, de algo que ellas no saben y que realizan inconscientes» (LFH 1, 70; W 12, 40). Es lo que ocurre con los grandes hombres, que satisfacen sus pasiones pero sirven los designios de lo absoluto. «Con la ruina de lo particular se produce lo universal... Se puede llamar a esto el ardid de la razóns ( $L F H$ I, 85; $W 12,49)^{21}$, que se manifiesta más aún cuando los grandes hombres históricos 
- «los grandes individuos en [de] la historia universals ( $L F H \mathrm{I}, 78 ; W 12,45$ )fracasan, aunque su fracaso comporta un progreso de la libertad. Más aún: el mal no ocurre en vano; de ahí que la astucia de la razón evoque los planteamientos de la teodicea ${ }^{22}$. Si antes hablábamos de abolición de la narratividad, ahora debería hablarse de abolición de la subjetividad individual.

Lo absoluto rcaliza su propio drama absorbiendo los dramas humanos, como se indica en el escrito sobre el Derecho Natural: «La pena es la restauración de la libertad y el criminal también queda libre... La relación del crimen y de la pena es un momento del absoluto mismo" ${ }^{23}$ (DN 53 y $54 ; W 2,480$ ). Por tanto, «la singularidad pura que existe en la muerte es su propio contrario, la universalidad ( $D N 53 ; W 2$, 479). Estamos ante ala tragedia que el absoluto juega consigo mismo, [a saber] él se engendra a sí mismo eternamente en la objetividad, se entrega, en esta experiencia que es la suya, a la pasión y a la muerte y de estas cenizas se elcva en su majestad» (DN 69; W2, 495).

Apoyándose en esa interpretación de la pena de muerte, escribe Richir con cierto patetismo: «Lo que, en la interpretación hegeliana de la pena de muerte, nos lleva ineluctablemente a indignamos es que des. precia precisamente la singularidad humana, el enigma irreductible que el ipse o sí mismo constituye por sí mismo... No le deja la menor oportunidad [al criminal] de realizar por si mismo la prueba [experiencia] de la conducción de su propia muerte a su particularidad, de su acceso a él mismo como a su propio enigma... Pensar que la singularidad pura, que vive la muerte, es su propio contrario, la universalidad, es pensar que no existe estatuto para la singularidad puras ${ }^{24}$.

Las dificultades de la posición hegeliana no se derivan de su critica del formalismo kantiano ni de su defensa de la mediación institucional y estatal. Se derivan de que
Hegel, en el proceso que relaciona al individuo con el Estado, distingue espíritu subjetivo y espíritu objetivo, pero separa del espiritu a la conciencia [individual]: «La cuestión - argumenta Ricoller- es cvidentemente de una gravedad esencial. Para Hegel, el término mismo de espíritu - Geist-implica una discontinuidad radical con toda conciencia fenomenológica, es decir, con una conciencia escindida de sí misma por la carencia y que hace depender su ser del reconocimiento de otra conciencia... Se puede uno preguntar si esta hipóstasis del espíritu, elevado por encima de la conciencia individual, incluso por encima de la intersubjetividad, no es responsable de otra hipóstasis, la misma hipóstasis del Estado" ${ }^{25}$. Se trata de la ontologización del espíritu y del Estado.

Ricoeur expone, a continuación, tres puntos decisivos. En primer lugar, podemos rechazar la hipóstasis hegeliana porque disponemos de una alternativa posibilitada por la quinta de las Meditaciones cartesianas de Husserl, que deriva de la relación intersubjetiva las comunidades -entre ellas, el Estado-y las instituciones. Las instituciones son reificaciones y objetivaciones de la interacción de los sujetos individuales. La razón práctica regula la dialéctica «libertad-institución". De acuerdo con Husserl, el espíritu objetivo se constituye «por la vía de la intersubjetividad ${ }^{26}$ de las conciencias individuales. Hcgel sustancializa las entidades colectivas; Husserl las desustancializa: lo social tiene valor de adjetivo, no de substantivo.

En segundo lugar, según Hegel el individuo se sabe en el espíritu y el espíritu, sc sabe en el Estado. Esa ciencia conduce a una disposición que permite abusar de los individuos, y puede engendrar la tiranía -peligro que ya había reconocido Platón-. Si la reificación y objetivación dependen de la interacción entre los individuos, el saber acerca de estas instituciones se resentirá de la probabilidad humana. No existe una teoría de la praxis: la 
razón práctica no es teoria de la praxis. Sólo existe la teoria de las cosas necesarias e inmutables; la razón práctica se sitúa en un terreno intermedio entre lo necesario y lo arbitrario. Pero esto garantiza la «sobriedad» de la razón práctica y «su apertura a la discusión y a la críticas ${ }^{2}$.

En tercer lugar, esa función crítica «desenmascara los mecanismos solapados de distorsión por los cuales legítimas objetivaciones de la relación comunitaria devienen alienaciones intolerables ${ }^{28}$. En tal sentido, «la sustitución del espíritu objetivo hegeliano por la intersubjetividad preserva los criterios mínimos de la acción humana» ${ }^{29}$, que permiten responsabilizar a los agentes de sus acciones. Sin ellos, se reifican las relaciones sociales. La explicación husserliana «adquicre valor de protesta»; de tal manera que, "por muy reificadas que estén las relaciones humanas, constituyen precisamente la desgracia y el mal de la historia, no su constitución primordial» ${ }^{30}$; adquiere, por tanto, «rango de instancia crítica a la que debe someterse también el Geist hegeliano» ${ }^{31}$. De ahi el interés que tendría la subordinación del espíritu objetivo a la intersubjetividad. (Ahora bien. Tal objeción vale para el Hegel de la madurez, pero no para sus escritos de juventud, que Ricoeur no tiene en cuenta en la discusión: estudiaremos csta matización más adelante.)

En Soi-même comme un autre, Ricoeur ha vuelto sobre el problema de la «renuncia a Hegel», para senalar, otra vez, el punto débil de la Aufhebung de la conciencia individual por el Estado. Como de costumbre, Ricoeur intenta comprender el proyecto hegeliano en su profundidad y le expresa su adhesión hasta tropezar con la dificultad, a su juicio, insuperable. En tal sentido, procede primero a un profundo elogio de la Sittlichkeit hegeliana, que «no ha dejado de instruirnos» ${ }^{32}$, considera, siguiendo a Eric Weil, que el Estado hegeliano es un Estado liberal basado en la Constitución. Es más: Hegel reconoce derechos a la conciencia, criticándola sólo cuando «la voluntad subjetiva se autonomiza de todo designio comunitarion ${ }^{33}$ - $\mathrm{fa}$ milia, sociedad civil, Estado-: lo que critica es la conciencia «abstracta, limitada y formals ${ }^{34}$ (PPD, $\left.\S 108,151 ; W 7,206\right)$, que condiciona y subordina su relación con el bien al deber (PPD \$ 133 y su Agr., 171; $W 7,250-51)$ y a la soledad del fuero interno $(P P D \S 136$ y su Agr., 173; $W 7,254 ;$ cf. también: PPD $\$ 137$ y su Agr., 174-5; $W 7$, 254-6 y 258; asimismo: $P P D \& 139,176-7$; $W 7,260-61)^{35}$; frente a la conciencia «abstracta» Hegel defiende la «conciencia verdadera», pero tal kconciencia verdadera» es la disposición ética, el spunto de vista ético» (PPD \$ 137, 174; $W 7,254$ ). La conciencia moral, «abandonada a su solo juicio, nunca se verá libre de confundir el bien y el mal» ${ }^{36}$. Con palabras de Hegel, «es así como esta interioridad de la voluntad es mala» (PPD \& 139 Obs., 176; W7, 261). Hay que reconocer con Hegel que el individuo «no deviene humano más que bajo la condición de ciertas instituciones; la obligación de servir estas instituciones es también ella una condición del desarro1 lo del agente humano... Es impresionante la requisitoria que Hegel ha dirigido contra la conciencia moral [kantiana] cuando ésta se erige en tribunal supremo con una altanera ignorancia de la Sittlichkeit en la que se encarna el espíritu de un pueblos ${ }^{37}$.

Pero el problema es el siguiente: la Sittlichkeit hegeliana significa la mediación institucional como instancia de juicio superior a la conciencia moral e independiente de ella. Ricoeur plantea la siguiente objeción: «QQué ocurre cuando la vida ética de un pueblo está fundamentalmente corrompida? ¿No es entonces cuando la integridad de la vida ética se refugia en la conciencia de aquellos individuos que la mentira y el miedo han dejado de intimidar?» 38. De otra mancra: «Cuando el espíritu de un pueblo es pervertido hasta el punto de alimentar una Sittichkeit mortífera, es finalmente en la concencia moral 
de un pequeño número de individuos, inaccesibles al miedo y a la corrupción, donde se refugia el espíritu, que ha desertado de las instituciones devenidas criminales» ${ }^{39}$. $Y$ es que «lo que finalmonte es inadmisible en Hegel es la tesis del espíritu objetivo y su corolario, la tesis del Estado erigido en instancia superior dotada del saber de Sir) ${ }^{40}$. De otra manera: lo grave consiste en la ontologización y sustanciación del Geist, al margen de las conciencias individuales.

2. Ernst Tugendhat ha expresado sus reparos, con notable originalidad, a lo largo de Autoconciencia y autodeterminación $^{41}$. La objcción de Tugendhat desemboca en la acusación de que, en Hegel, es abolida la posibilidad de la crítica.

Para la filosofia moderna, de Descartes a Hegel, el concepto de autoconciencia se refiere a un saber de sí mismo como principio metodológico de la filosofía y como fundamento de una existencia ilustrada y autónoma. De ahí que Hegel salude con alborozo la aparición de Descartes en sus Lecciones sobre la historia de la filosofia ${ }^{42}$. "Aquí, ya podemos sentirnos on nucstra casa y gritar, al fin, como el navegante después de una larga y azarosa travesía por turbulentos mares: itierra!» (LHF III, 252; $W 20,123$ ). De Descartes parte la autoconciencia de carácter epistémico y basada en la relación sujeto-objeto.

Pero Hegel, sobre la huella de Fichte, considera la autoconciencia como un comportarse práctico consigo mismo: hay que entenderla como un hacerse, como un construirse; la persona no es sólo sustancia con estados internos o cxtcrnos, sino también un ser activo en contextos intersubjetivos y con capacidad de autodeterminarse -es lo que quiere ser y lo que hace-. $Y$, por otro lado, introduce un elemento de gran importancia: la relación consigo mismo se constituye en la intersubjetividad. La vida verdadera y buena consiste en cla relación afirmativa del individuo con su entorno, con su prójimo, etc., sin que por ello el individuo pierda su identidad». Tal identidad es una kidentidad de lo diferente, restablecimiento de la unidad a partir de la no identidad $*{ }^{43}$, lo que implica una superación de la alienación y el acceso a la universalidad: «El yo que es el nosotros y el nosotros que es el yow ${ }^{44}$ ( $F 113 ; W 3,145)$.

Tugendhat se hace eco de la crítica que la Escuela de Heidelberg - Dieter Henrich, Ulrich Pothast, Conrad Cramer- ha realizado de la autoconciencia hegeliana: «Todos los intentos de hacer comprensible la estructura del saber de si mismo conducen a paradojas». Pero hay que buscar una salida a tales paradojas, «supuesto que tengamos interés en una praxis gobernada por la razón». Tal salida - que no realizó la citada Escuela- podría lograrse recurriendo a otros «puntos de vista", ya que «de otra manera permaneceríamos atascados en una interpretación inmanente, como es habitual en la literatura sobre Hegel" ${ }^{45}$. Los otros puntos de vista que utiliza Tugendhat son, principalmente, los de Heidegger, Mead y Wittgenstein.

Tugendhat se enfrenta a Hegel con dos objeciones muy graves. Una se refiere al esquema «sujeto-objeto» sobre el que se basa la autoconciencia hegeliana; esta dificultad es superada por Heidegger. La otra se refiere a que Hegel no introduce la pregunta por la verdad ni la discusión cuando la autoconciencia aspira a la vida buena; esta dificultad es resuclta, según Tugendhat, por George Herbert Mead.

Heidegger es «el único que encontró una clarificación estructural» para la relación práctica consigo mismo. En las «Anotaciones» a Psicología de las concepciones del mundo de K. Jaspers, nos advierte Heidegger que el "soy» no es una mera variante del «es» aristotélico. El ser, en la situación del "soy", es considerado como haber de ser; cuando digo "soy", no realizo una mera contemplación de mi ser - no me relaciono estêticamente con él-; cuando digo "soy" me estoy preocupando por mí: 
la relación con el ser adquiere la forma de la preocupación; ese haber de ser es la existencia - como cxplica en Ser y Tiempo-. Este comportarse no es una representación, ni es conciencia de algo, sino que consiste en afirmar o negar el propio ser, en decir «sín o «no" frente a cl. Este planteamiento queda lejos de la identidad de la subjetividad con la objetividad en la cual se cumple la autoconciencia hegeliana ${ }^{46}$.

Mead, por su parte, introduce una tematización revolucionaria. La autoconciencia consiste en "hablar consigo mismo", que es, a su vez, una interiorización del shablar con los otros»; este hablar con los otros puede significar hablar con otro en grupo o hablar con todo ser racional. En esto, enlaza con Hegel. Pero la estructura de esta hablar consigo y con los otros sólo puede consistir en tomar posición con el "sís o con el «no» y, además, en preguntar por la verdad: Mead añade a Heidegger una responsabilidad que implica la pregunta por la verdad; cuando me enfrento con mi haber de ser -con el «sî o el «no»afronto la verdad. Mead introduce un elemento crítico ausente en los planteamientos hegelianos y asimismo en los heideggerianos: la intersubjetividad es «una intersubjetividad de sujelos crílicos de sí mismos y recíprocamente entre sí respecto de la verdad*. En Hegel los sujetos no se preguntan por la vida buena: se trata de una «relación cerrada con la verdad» 4 ,

Pero relacionar a Hegel con Heidegger y Mead sólo es posible desde la problemática de la libertad: en esta problemática Hegel los supera. El comportamiento práctico consigo mismo desde la libertad de la voluntad, desde la voluntad racional es expuesto en la Introducción a los Principios ( $P P D \$ 21-\$ 24,84-6 ; W 7,71-5$ ) y en la Enciclopedia 48 (E \$469-\$482, 418-427; $W 10,288-302$ ).

La gran dificultad del planteamiento hegeliano está en su naturalismo ético ${ }^{49}$, que se refleja en este pasaje: «La sustancia que se sabe libre, en la que el deber-ser absoluto es igualmente ser; ticne realidad como espíritu de un pueblo... La persona cumple así su deber, como suyo y como algo que es, sin elegir reflexivamente, y en esa necesidad se posec a sí misma y posee su verdadera libertad» $(E \S 514,442 ; W 10$, 318), El deber es identificado con ol ser. Por otro lado, las leyes e instituciones de la comunidad son uexistentes en sí y para sím (PPD \& 144, 191; $W 7,294)$ y constituyen «una autoridad y un poder absolutos e infinitamente más sólidos que el ser de la naturaleza” ( $P P D \$ 146,192 ; W 7,295$ ).

Así, «Hegel no admite la posibilidad de una relación crítica, auto-responsable con la Comunidad o con el Estado: más bien lo que se nos dice es que las leyes existentes tienen una absoluta autoridad, que lo que el individuo tiene que hacer está establecido por la Comunidad. La conciencia moral privada del individuo tiene que desaparecer y en el lugar de la reflexión entra la confianza: esto es lo que Hegel quiere decir con la superación de la moralidad en la eticidad» ${ }^{50}$. ¿Qué es la libertad para Hegel? Cumplir las exigencias de la comtnidad. «En una comunidad ética es fácil decir qué debe hacer el hombre, cuáles son los deberes que debe cumplir para ser virtuoso. Él no tiene que hacer otra cosa que lo que le es indicado, señalado y conocido a partir de sus relaciones» (PPD $\$ 150$ Obs.; 194; $W 7,298$ ). En lugar de la elección reflexiva, entra entonces la confianza, como se deduce de este pasaje: «De esta manera la sustancialidad ética ha obtenido su derecho y éste su validez. Dicho de otro modo: en ella han desaparecido la obstinación y la conciencia del individuo que fuese para sí y se opusiese a ella» ( $P P D$ $\S 152,196 ; W 7,302-3$ ).

Para Hegel, la eticidad existente-presente es lo racional. Lo existente es asumido sin posibilidad de contestación. Se podría aducir que, de acuerdo con Hegel, lo real no coincide con lo fáctico. En tal caso, lo real se desplaza al futuro. Enton- 
ces, se impone el deber. Pero Hegel niega cl deber. Por todo ello, «la filosofía de $\mathrm{Hegcl}$ es consciente y explícitamente la filosofia de la justificaciôn de lo existente... Pcro la justificación de lo existente es exactamente lo contrario de la pregunta práctica por la verdad ${ }^{51}$. Tal pregunta significaría, en el contexto hegeliano, la vanidad de la subjetividad. La libertad es concebida como unidad de individuo y comunidad: «El sujeto es libre realmente sólo cuando se sabe uno con lo objetivo, respecto de lo cual se relaciona activamente, porque ya no depende de algo extraño a él» ${ }^{52}$. Se pierde, así, el sentido que el têrmino «libertad» tiene en el lenguaje común. Lo mismo ocurre con la verdad, que es concebida como unidad de sujeto y realidad.

Supongamos el Estado más bueno: no lo sería, si exigiera -como es el caso, según Tugendhat- la renuncia a la responsabilidad, si exigicra una adhesión incondicional. $Y$ aduce el pasaje en que se apoyan los detractores del Estado hegeliano: «El Estado, en cuanto realidad de la voluntud sustancial, realidad que ésta tiene en la autoconciencia particular elevada a su universalidad, es lo racional en sí y para sî. Esta unidad sustancial es el absoluto e inmóvil fin último en cl que la libertad alcanza su derecho supremo, así como este fin último tiene un derecho supcrior a los individuos, cuyo supremo deber es ser miembros del Estado» (PPD \$ 258, 258; W7, 399).

3. Habermas opone reparos parecidos a los anteriores, pero expone previamente una tesis hegeliana defendible, la contenida en los escritos juveniles y en algunos de Jena: frente a ellos perderían su validez las dificultades aducidas anteriormente. En tal sentido, habría que afirmar que la posición de Mead — con la que Tugendhat se propone corregir a Hegel - está ya en los escritos juveniles. Se verá más adelante. Pero Habermas señala y explica inmedia- tamente el abandono por Hegel de su tesis juvenil.

II. LHemos de aceptar la propuesta de Ricoeur: aRenunciar a Hegels, que hemos referido varias veces? ¿Debemos, para expresarlo con él mismo de otra manera, «salir del hegelianismo», debemos elegir el «cxodo fuera del hegelianismow? 53

La recomendación no resulta tan clara. La cuestión es más compleja de lo que aparenta. La complejidad nos obliga a hacer algunas aclaraciones y precisiones antes de entrar en una confrontación con los argumentos expuestos.

Debemos referinos, en primer lugar, a la ambigüedad formada por el sistema y el método (dialéctico), que pueden ser separados. Si negáramos la posibilidad de tal separación, no podríamos explicarnos lo que Marx se incorporó de Hegel; ni el entusiasmo de Lenin por la Lógica hegeliana; ni el evolucionismo de Darwin -según Nietzsche: «sin Hegel no hubiese tenido lugar Darwins ${ }^{54}$-; ni las huellas hegelianas en Kierkegaard... No deberiamos perder la riqueza de análisis e intuiciones que nos ofrece el método. Pero es que, además, el «vicio» sistemático está ausente de algunos escritos hegelianos - los juveniles y, en ciertos aspectos, los de Jena-.

Por otro lado, muchas expresiones del discurso hegeliano - las más decisivashan sido objeto de malentendidos. Como observa Marini, «las palabras tienen sus aventuras semánticas» 55 , 10 que, en algunos casos, conlleva un empobrecimiento de su significado: es lo que ha ocurrido con bastantes términos y expresiones hegelianas. Una de nuestras tareas consistirá en devolver a tales expresiones - por ejemplo, «sociedad civil», «Estado», etc.- el significado exigido por el contexto.

También resulta interesante estudiar algunos temas de Hegel desde la metáfora -que es sustancial y permanente en su obra-. Su idealismo especulativo ha sido considerado como una metáfora - «Hegel 
piensa metafóricamente» ${ }^{56}$-: metáfora que esconde significados realistas. Precisando y ampliando la propuesta de Mercier-Josa, diríamos que desmetaforizar a Hegel equivale a desidealizarlo, aisiarlo del sistema especulativo. Si los desmetaforizamos, los planteamientos hegelianos se muestran ricos en recursos para la solución de los problemas políticos.

A. Afrontemos la primera dificultad: abolición del tiempo y de la historia.

Catherine Malabou ha realizado un estudio sobre la función de la plasticidad temporal en la dialéctica hegeliana, en el que se dedica a refutar la acusación heideggeriana ${ }^{57}$ de que, en Hegel, opera una visión vulgar del tiempo: «El sistema hegeliano como clausura sobre sí mismo de un presente intemporal, que anula de antemano toda trascendencia y todo advenimiento del acontecimiento». Sin embargo, desde la plasticidad, el porvenir no es, en Hegel, un simple momento del tiempo - un ahora que no es todavía presente-, sino el nombre dado a la estructura de anticipación inmanente a la subjetividad tal como ella se despliega en el sistema ${ }^{58}$. Esa estructura consiste en un "ver venir" (se espera algo, pero no se sabe qué).

La autora, para apoyar su tesis, parte de la comprensión hegeliana de la proposición. Debe rechazarse la proposición entendida tradicionalmente como predicación, o sea, como mera yuxtaposición de sus términos - sujeto, cópula, predicado-, sin relación de necesidad entre ellos; el predicado o accidente le llegaría al sujeto desde fuera: el sujeto no produciría sus propias determinaciones. La proposición especulativa o filosófica implica una relación que consiste en una identidad dialéctica: el predicado emerge necesariamente del sujeto. Malabou añade: accidente, en griego, se dice sumbebekós, de sumba-nein, que significa, a la vez, «seguir lógicamente» y uacontecer» o «sobrevenir»: este recurso etimológico permite a la auto- ra «encontrar el eslabón entre plasticidad y temporalidad» y, así, «la proposición es el lugar en que el sujeto se promete el porvenir, y la plasticidad permite percibir el juego conjugado de la necesidad y de la sorpresa [novedad] en la filosofía especulativa». El tiempo hegeliano es tiempo lógico y tiempo cronológico. Esa relación del sujeto con el accidente posee carácter plástico; como explica el mismo Hegel en el prefacio a la Fenomenologia, «sólo logrará adquirir un valor plástico la exposición filosófica [la filosofía] que sepa eliminar rigurosamente el tipo de las relaciones usuales [establecidas por la tradición] entre las partes de la proposición» ( $F$ 43; $W 3,60)^{59}$. En arte, plasticidad significa capacidad de recibir y dar formas, capacidad de evolucionar. Como inmanente a la subjetividad, la plasticidad significa «el sujeto como instancia originaria de recepción y de donación de su propia forma, posibilidad de su auto-determinación» ${ }^{60}$.

La plasticidad es solidaria de la dialéctica - cuyo motor es la negatividad-. La relación que sostiene a ambas consiste en «no ser lo que se es». En tal proceso, «la adquisición de la forma es a la vez anulación de la forma. El acontecimiento sc vuelve contra sí mismo - Hegel lo muestra sin cesar-: eso explica que los lectores piensen que, en Hegel, no existe el acontecimiento" ${ }^{61}$.

La autora acaba proponiendo suna interpretación del "saber absoluto" que no lo reduce a una clausura del desarrollo espiritual en el éxtasis de un presente eterno, sino que lo considera como la apertura de un tiempo nuevos ${ }^{62}$.

La tesis es profunda y muy brillante. Quizá se le pueda oponcr que la contingencia forma parte de «la tragedia que el Absoluto juega consigo mismo eternamente», en la que «el Absoluto se engendra eternamente cn la objctividad y... se cntrega a la pasión y a la muerte y de estas cenizas se eleva a la gloria» - como declara Hegel en el artículo sobre el Derecho 
Natural (DN 69; W 2, 495). Todo estaría decidido de antemano, incluida la contingencia.

Para que la interpretación de Malabou resulte eficaz, se requiere previamente que desmetaforicemos el planteamiento hegeliano: la des-metaforización o des-idealización pondría de manifiesto que a Hegel no le ha pasado desapercibido ningún registro de la realidad: tampoco el tiempo como creación de novedades. Resumiendo: Hegel no bloquea la narratividad, aunque la interprete al modo idealista.

Debemos tener en cuenta, con Koyré, que la "mayor originalidad" de Hegel consiste en «su insistencia en el futuro», en «otorgar al futuro primacía sobre el pasado» ${ }^{63}$. Hannah Arendt sigue a Koyré en su exposición sobre la relación del tiempo con la voluntad en Hegel: «El tiempo es generado por el desasosiego innato del espíritu, por su tendencia hacia el futuro, por sus proyectos y su negación del presente estadion ${ }^{64}$.

Tras la transparencia entre historia y verdad —su mediación total y absolutalate la tesis de que la razón y la verdad son inmanentes a la historia y no se limitan a la condición de mero deber. Esa tesis, por otro lado, no implica que se dé el final de la historia en una configuración histórica determinada, no supone la eliminación de la narratividad. También Koyré recomienda distinguir, en la obra de Hegel, entre sistema y dialéctica: el sistema exige el cierre de la historia, pero la primacia concedida al futuro exige - como comenta Arendt- que el tiempo no termine jamás en tanto que existan los hombres sobre la tierra» ${ }^{65}$. Como advierte Ricoeur mismo, «no nos detendremos tampoco en el prejuicio más tenaz según el cual Hegel habría podido creer que la historia habría llegado a su término al ser comprendida por la filosofia hegeliana: los indicios del inacabamiento de la historia del Estado son bastante numerosos y bastante claros, en Hegel mismo, como para dar crédito a esta necia opinión» ${ }^{66}$.

Hay que citar el bello pasaje de la Conclusión de las Lecciones sobre la historia de la, filosofia: "Hasta aquí ha llegado el Espiritu del Mundo... Lo que nuestra mirada abarca rápidamente en el recuerdo tardó largos siglos en realizarse. En la realidad, el concepto del Espíritu aspira a una evolución totalmente concreta, a plasmarse en una existencia externa, en toda su riqueza, a desarrollar ésta y a brotar de ella. Avanza sin cesar, pues sólo el Espíritu es progreso. A veces parece como si se perdiese y olvidase; pero, contraponiéndose interiormente, se desarrolla sin cesar interiormente... hasta que por fin, fortalecido dentro de sí, rompe la corteza terrestre que le separaba de su sol, de su concepto; revestido de nueva juventud, calza las botas de siete leguas" ( $L H F$ III, 513; $W 20,456$ ).

La reconciliación hegeliana no sólo afecta a Prusia, afecta a la historia entera, entendiendo a ésta como progresiva racionalización. Como afirma D'Hondt, Hegel «justifica todos los órdenes establecidos sucesivamente» ${ }^{67}$; por tanto, justifica el derrocamiento de la figura envejecida y la instauración de la nueva. No existe el final de la historia. Se trata del espíritu del mundo, de la historia a la que se subordinan los pueblos y las instituciones: es «el gran viento de la historia, aunque este viento sople en una cabeza especulativa» --escribe D'Hondt en otro lugar-. Es decir: "Cada etapa del viaje del espíritu acaba delante del tribunal de la universalidad terrestres; el tribunal es la historia del mundo: pcro no se trata de proceso jurídico, sino de evolución. Aquí no hay inocentes ni culpables: «El tribunal no castiga culpables, como Kronos, liquida sobrevivientes: todo lo anacrónico pasa: estructuras familiares, sistemas económicos, pueblos y civilizaciones. ¿Cómo hubiera podido Hegel considerar eterna la Prusia de Federico Guillermo III?». Y, si la historia 
es el tribunal, es que no hay tribunal supremo alguno trascendente: «El "tribunal" hegeliano no se sitúa por encima de la mêlée. Forma parte de la disputa de los pueblos; mejor: no es más que la disputa, el proceso mismo del conflicto en el que se implican, la ley dialéctica de contradicción y de sobrepasamiento, inmanente, que siguen todas las cosas en este mundo 68 .

La filosofia hegeliana de la historia permite dos lecturas - que ha sugerido Solange Mercier-Iosa-: el espíritu puede extender su actividad a otros pueblos, desposeyendo a Europa de su exclusividad para detentar el universal concreto, pudiéndose afirmar, entonces, que el espíritu emigra hacia otros pueblos para «trabajar» negativamente $\mathrm{y}$ resolver las contradicciones, pero puede afirmarse también que Europa aún no ha cancelado las contradicciones de la sociedad civil, encontrándose, en tal caso, en la situación tan injusta que describen los Principios: una masa empobrecida por debajo del nivel de la «dignidad de subsistir gracias al propio trabajo y la propia actividad» (PPD $\$ 244,251 ; W 7$, 389): el pueblo germánico-Europa-aún no ha madurado, aún «trabaja» en la reconciliación de la libertad subjetiva con la voluntad sustancial, ya que «la sociedad civil fracasa en la satisfacción de las necesidades de todos por el trabajo de cada uno», ya que «esta dialéctica [de la socicdad civil] obtiene como resultado el oponer una gran masa de hombres tendencialmentc excluidos tanto de la producción como del consumo de la riqueza general y de la cultura a un pequeño número de individuos en cuyas manos se concentran riquezas desproporcionadas $\%{ }^{69}$.

Una objeción muy tópica, en relación con la filosofía hegeliana de la historia, se refiere al ardid de la razón. También aquí se impuso el malentendido. También aquí hay que aplicar la desmetaforización; a ello nos ayuda esta observación de Collingwond: «La razón cuyos planes se ejecutan en la historia no es, para Hegel, ni una razón natural abstracta ni una razón divina trascendente, sino la razón humana, la de las personas finitas. Y la relación que él afirma entre razón y pasión no es una relación entre Dios o la naturaleza, como racionales, y el hombre, como apasionado, sino una relación entre la razón humana y la pasión humana». Esta visión «anuncia en verdad una nueva concepción del hombre, dinámica en vez de estática, y significa que Hegel trabaja para apartarse de la teoría abstracta y estática que prevaleciera en el siglo xvirt» 70 .

Algo parecido ocurre con la expresión Espíritu del Pueblo. El término «del» posee dos significados: pasivo -el pueblo sería mero instrumento del espíritu (éste seria el sujeto)- o activo - el sujeto sería el pueblo y el espíritu la relación del pueblo consigo mismo, el grado de su libertad-. La trascendencia de la primera alternativa - de carácter pasivo y que se relaciona con el ardid - es una forma mistificada de expresar la necesidad - condicionamientos, determinaciones con los que, según Marx, los pueblos producen su vida-: esa necesidad condena a cada pueblo a morir y ser relevado. Aunque para $\mathrm{Hegel}$ el espíritu de cada pueblo es un grado de libertad -sentido activo-, al final la necesidad lo condena a desaparecer -sentido pasivo- ${ }^{71}$.

B. Corresponde, ahora, estudiar la acusación de bloqueo de la subjetividad y conciencia individuales, en sus dos vertientes principales: imposibilidad de actuación de la conciencia individual frente al espiritu objetivo y frente al Estado, e imposibilidad de la capacidad critica y contestataria.

1. Examinemos primero si la identidad considerada como identidad de la subjetividad y de la objetividad - identidad total gestada por el absoluto - bloquea la autonomia y el protagonismo de la subjetividad individual.

a) Como hemos indicado ya, la acusación valdría para el Hegel de la madurez, 
pero no para sus escritos de juventud. Habermas también ha objetado a Hegel su adhesión a la filosofía de la reflexión subjetiva que caracteriza a la modernidad -aunque ésta resulte corregida por aquél- pero percibe en los escritos de juventud una vía para la pacificación de las contradicciones de la modernidad que no implicaba el esquema «sujeto-objeto», típica de la filosofía moderna: el Hegel juvenil aborda la pacificación desde la acción comunicativa ${ }^{72}$.

i) En plena juventud, Hegel se enfrenta a la crisis que caracteriza a su tiempo. De ella nos hablan sus escritos jiveniles: los politicos expresan la crisis de una manera más directa y sugestiva que los teológicos: aluden a las contradicciones y al impulso humano que aspira a resolverlas con el cambio de la realidad social. Así, en La Constitución de Alentania escribe, refiriéndose al ámbito jurídico de la vida social: «Las leyes han perdido su vieja vida, la verdadera vida actual no ha sabido estructurarse en leyes" ${ }^{73}$ (EP $35 ; W 1$, 465). La política y la religión han devenido fuerzas petrificadas y extrañadas -aljenantes-. De ahí esta manifestación en otro escrito de la misma época ${ }^{74}$ : «La imagen de tiempos mejores y más justos han tomado violentamente asiento en el alma de los hombres y la nostalgia, el urgente deseo de un estado más puro y más libre han movido a todos los ánimos y los enfrentan a la realidad" ( $M B$, traducción nuestra; W 1, 268-9).

Hegel intuía, entonces, que la solución dada por la filosofía de la reflexión no cancelaba el desgarramiento, producía falsas identidades, generaba la pacificación «mediante la violencia de una subjetividad represoras ${ }^{75}$. En sus ercritos de juventud, Hegel resuelve el problema mediante la razón comunicativa que se despliega en la vida intersubjetiva. Habermas ha comentado el conocido pasaje sobre el delito que aparece en El espintu del cristianismo y su destino ( $W 1,342$ y ss.): en «una situación social en la que todos los miembros alcanzan sus derechos y satisfacen sus necesidades» el culpable introduce una disociación y «viola las relaciones éticas»: al oprimir las vidas ajenas, la totalidad se le vuelve extraña y es sentida como un «destino hostil»: la «perturbación de un equilibrio intersubjetivo desemboca en una conciencia desdichada, hasta que el culpable acaba reconociendo «en la aniquilación de la vida ajena la carencia de la propia». Lo perturbado y perdido - y que, ahora, se añora- no es una relación sujeto-objeto, sino una relación intersubjetiva - «mundo intersubjetivamente compartidos ${ }^{76}$, en el que funciona el reconocimiento recíproco- Hegel se aparta de la modernidad basada en la relación reflexiva entre sujeto y objeto. [Contrasta esta visión - desde la intersubjetividad comunicativa y colaboradora, que actúa en la polis griega y en el cristianismo primitivo-con cl tratamiento dado al mismo problema (el delito) en el artículo sobre el Derecho Natural - desde el absoluto, que no concede oportunidad a la subjetividad individual-].

Nos explicamos que, en su magistral estudio sobre Kierkegaard, Jean Wahl, haya aludido a las huellas de Hegel en el padre del existencialismo; incluso se atreve a hablar de afinidades entre Kierkegaard y el joven Hegel - «todavía no hegeliano», «Hegel pre-kicrkegaardiano»-: «Nos vemos impulsados a preguntar si en los fragmentos teológicos de Hegel no se han esbozado ideas que encontrarán su verdadero desarrollo, no en el sistema posterior de Hegel, sino en el pensamiento de su adversariom $n$.

Esa orientación deja huellas en la Filosofia del espiritu de Jena y en el Sistema de la eticidad. El contexto no es, aqui, el delito, sino la autoafirmación del yo. En estas obras, el yo solo se afirma auténticamente al ser reconocido por los otros, en su identidad con la totalidad que no anula las particularidades. Cada concien- 
cia, sin perder su diferencia y autonomia, participa en la totalidad, actuando cn tres campos: lenguaje, trabajo y familia -amor-.

El espiritu es «el medio en el que un yo comunica con otro yo y a partir del cual, como de una mediación absoluta, se forman ambos sujetos recíprocamente»; la conciencia es «el medio en el que los sujetos se encuentran, pero de modo que, sin encontrarse, esos sujetos no podrían existir como sujetos» ${ }^{78}$. El universal concreto consiste en la comunidad de los sujetos autónomos: «Pueden los particulares identificarse los unos con los otros y, sin embargo, mantenerse a la vez como no idénticos los unos frente a los otros. La idea original de Hegel consiste en que al yo sólo se lo puede concebir como autoconciencia si es espíritu, si pasa de la subjetividad a la objetividad de un universal, en el que sobre la base de la reciprocidad, los sujetos que se saben a sí mismos quedan asociados como no idénticos» ${ }^{79}$.

ii) Pero Hegel abandona ese camino -razón comunicativa en vez de razón reflexiva-, recién descubierto. Ese giro ocurre en Jena mismo.

En un texto de esa época escribe Hegel: «La necesidad de la filosofia surge cuando el poder de unificación [reconciliación] desaparece de la vida de los hombres, y los opuestos pierden su viva relación e interacción y cobran autonomía... En la escisión dada, [la filosofía] es el intento necesario de superar la contraposición de la subjetividad y de la objetividad cristalizadas [petrificadas]... En la actividad infinita del devenir y del producir la razón ha unificado lo que estaba dividido y ha rebajado la escisión absoluta a una escisión relativa, que está condicionada por la identidad originaria ${ }^{80}(D F S C H 20 ; W 2,25)$. Pero iqué filosofia? La modernidad le exigía operar desde sí misma $y$, por tanto, desde la reflexión. Hegel desca mantenerse en la «autofundamentación de la moderni- dad» ${ }^{81}$, que implica una ruptura con el pasado. Pero la totalidad ética comunicativa estaba ligada indisolublemente a la política antigua y a la comunidad cristiana primitiva.

Por otro lado, en la época de Jena, Hegel se familiariza con la economia política; ésta le pone de manifiesto que la sociedad civil no contiene ninguna similitud con las sociedades antiguas. La sociedad moderna es una socicdad despolitizada: la economía se ha emancipado del poder, constituyendo dos esferas distintas: valor de cambio y poder. Ya no se puede recurrir al ideal antiguo.

Ahora bien, Hegel percibe también que la filosofía moderna - la filosofía de la reflexión- no resuelve el problema, viéndose obligado a corregirla. La filosofía de la reflexión propone una identidad [unificación, reconciliación] falsa. Hegel explica en qué sentido lo es: «Una falsa identidad es la relación de causalidad entre lo absoluto y su manifestación, pues a esta relación subyace la contraposición absoluta. En ella subsisten ambos opuestos, pero con rango diferente; la unificación es violenta. El uno subordina al otro; uno domina, el otro resulta sometido...; la identidad, que debe ser absoluta, es sólo una identidad incompletas (DFSCH 53; W2, 48). Lo infinito de la filosofía de la reflexión es algo puesto por el entendimiento - que es «una razón que se agota en la negación de lo finito» ${ }^{82}$.

La identidad verdadera y completa se encuentra en el absoluto que genera y unifica a la subjetividad y la objetividad. Como ha señalado muy bien Marcel Mery, Diferencia y Creer y saber, «delatan constantemente una cxaltación, no sentimental, sino intelectual, debida al descubrimiento del Absoluto» ${ }^{83}$. El absoluto descubierto "no es ningún término de la relación, el yo o cl no-yo, lo finito o lo infinito, la necesidad o la libertad, es para Hegel la relación misma». Es un absoluto cuya "consistencia y movimiento" consiste en 
«impedir y contrarrestar todas las absolutizaciones [unilaterales] ${ }^{84}$. El absoluto no es previo al proceso del mundo. $O$ de otra manera: el sujeto de la relación es la relación misma. La trinidad filosófica «espíritu-naturaleza-espíritu» es de carácter monista. Pero Hegel recoge todos los términos y momentos de la relación: la identidad pasa por las diferencias, por la noche de la contradicción hacia la luz de la identidad absoluta: por el calvario - pasión-y Viernes Santo de la contradicción hacia la Pascua de la totalidad. Estamos ante la «fiebre de construcción dialéctica» que le conducirá a la Enciclopedia ${ }^{85}$. La subjetividad ya no es, asi, un poder represor. Pero tal solución implica un gran coste, pues «con ese concepto del absoluto Hegel cae por detrás de las intuiciones de su época de juventuds ${ }^{86}$.

El problema de la sociedad moderna es la mediación de lo particular y lo universal. Esa mediación puede realizarse mediante dos fórmulas o modelos: monológico y dialógico. A partir de Jena, Hegel opta por el modelo monológico: un absoluto como subjetividad infinita que se extraña en la objetividad renaciendo de esas cenizas y accediendo a la gloria del saber absoluto, en cuyo autoconocimiento lo universal y to particular se unifican. Inaugura, así, lo que será su filosofía definitiva: el idealismo dialéctico ${ }^{87}$.

Resulta muy interesante contrastar las dos vías, los dos modelos. La dialéctica de la relación intersubjetiva de los escritos de juventud va asociada a una srelación de interacción entre dos oponentes iguales en principio». En cambio, la dialéctica de la relación entre el absoluto y sus uotros» excluye el diálogo: el otro - la naturaleza, la conciencia subjetiva- no es más que «la imagen en negativo» del absoluto. Esta dialéctica monológica incluye la dialéctica del sacrificio, como explica Hegel en el artículo sobre el Derecho Natural, donde se nos habla de la tragedia que el mismo absoluto vive eternamente en si mismo:
«En la totalidad ética se escenifica la tragedia ${ }^{8}$ que el Absoluto juega (representa) consigo mismo eternamente, o sea, el Absoluto se engendra eternamente en la objetividad y en esta forma suya se entrega a la pasión y a la muerte y de estas cenizas se eleva a la gloria» ( $D N 69 ; W 2,495$ ). Afirmación semejante aparece al final de Creery saber: «La idea de la absoluta libertad [implica] el dolor absoluto o el Viernes Santo especulativo, que era ya histórico, [implica] restablecerlo en toda la verdad y la dureza de su ateísmo, dureza desde la cual únicamente puede y tiene que resucitar la suprema totalidad en toda su seriedad y desde su más profundo fundamento, a la vez omniabarcante $y$ con la figura de la más risueña libertad ${ }^{89}(C S 194 ; W 2$, 432-3).

Estos planteamientos llevados al terreno de la sociedad civil y del Estado hacen que la superación de la desgarradura de la primera se resuelva con el segundo. La universalidad de la totalidad ética se sobrepone al individualismo de la sociedad modema. Las instituciones mediatizan a la subjetividad. La lógica de lo absoluto que se extraña y se recupera «impone el institucionalismo de un Estado fuerte», el «enérgico institucionalismo» de la filosofía del derecho de Hegel que sustituye a la *autoorganización democrática» ${ }^{90}$. Todo está pre-juzgado y pre-decidido.

Paradójicamente, con esa solución acaba imposibilitando la crítica de la modernidad, que se había propuesto. En su artículo «Sobre la esencia de la crítica filosófica», de la época de Jena, Hegel estudia dos clases de crítica. Una se refiere a la crítica de la vida religiosa y política en sus formas petrificadas, cristalizadas, positivizadas - vida reprimida y anquilosada-. La otra se relaciona con el relevo de la filosofía de la reflexión de Kant y Fichte: la filosofía de lo absoluto significa la objetividad de la razón - contra la cual no valen los lamentos de la conciencia subjetiva -; la crítica se dirige ahora a los 
impacientes. Esta actitud inspira el Prefacio de los Principios de la filosofia del derecho, y se insinúa ya en la segunda redacción de la Introducción a La Constitución de Alemania. De ahí el comentario de Habermas: «Hegel puede descargar a la filosofía de sus esfuerzos críticos dirigidos a confrontar la corrupta existencia de la vida social y política con su concepto, después de que reconoce con un suspiro de alivio que el espiritu ha dado un tirón, que el principio de la razón se ha presentado en la realidad y se ha tornado objetivo. Es tan sólo cuestión de tiempo y de las circunstancias contingentes cuándo pasará la nueva época por encima de la oposición de aquellos que le oponen resistencia impotentemente y será reconocida universalmente en su principio. Por vez primera ahora, Hegel puede darse por satisfecho con reconocer al espíritu que se ha tornado objetivo... y volverse criticamente contra aquellos que aún no han entendido la lección de la historia mundial. Un indicio vendría representado por la victoria de Napoleón sobre Europa. Éste es el tenor del escrito de combate [1817] contra los Estados provinciales württemburgueses» ${ }^{\text {! }}$.

iii) Tras hacernos cargo de las dificultades derivadas de esta vía "absolutista» y monológica, debemos tener en cuenta nuevamente que, antes de esa opción, Hegel recorrió otra vía y propuso otra solución, aunque después las abandonara. Se trata de la vía dialógica de los escritos de juventud. En resaltarla -insistimos - ha puesto gran énfasis Habermas: «En la universalidad de un consenso no forzado, alcanzado entre iguales y libres, queda abierta a los individuos una instancia de apelación a la que pueden recurrir incluso contra las formas particulares de concretización institucional de la voluntad común. En los escritos de juventud se mantenía todayía abierta la opción de desarrollar la totalidad ética como una razón comunicativa encarnada en un plexo de vida intersubjetiva. Por esta línca, una autoorganización democrática de la sociedad hubiera podido ocupar el lugar del aparato estatal monárquico» ${ }^{92}$.

b) Por otro lado, la conciencia individual aparece, en algunas secuencias de las obras de la madurez, como autónoma, en el sentido de que no le es impuesto todo como decidido de antemano.

La efectividad o realidad verdadera se debe al Concepto que la alcanza gracias a su trabajo negativo - anulación de sus determinaciones-y positivo-producción de nuevas determinaciones-: el Concepto, mediante la contradicción, disuelve sus determinaciones para crear otras. La nadificación que el Concepto realiza en su trabajo da paso a lo nuevo. La contradicción es la prueba de fuego, la encrucijada, como explica el mismo Hegel en la Ciencia de la Lógica ${ }^{93}:$ «Algo es viviente sólo cuando contiene en sí la contradicción y justamente es esta fuerza de contener y sostener en sî la contradicción. Pero si algo existente... no puede tener en sí mismo la contradicción, entonces ésta no es [su] fundamento, sino que perece en la contradicción» $(I .387 ; W 6,76)$-. Por eso, la efectividad puede truncarse: como señala tan oportunamente Rosenfield, "si no se tiene cuidado, podría concluirse que, como el orden del mundo lleva un contenido lógico, las instituciones políticas y sociales que lo integran son verdaderas. Nada más contrario a la elaboración hegeliana». Hay que afirmar, más bien, que la realidad social y política es «esencialmente portadora de un poder para convertirse en otra distinta de lo que es» ${ }^{94}$.

El citado pasaje de la Lógica sc ascmcja a otro de la Filosofía del espiritu II de Jena. También aquí se trata de una bifurcación y de una ambigüedad. Refiriéndose a la noche de las imágenes -imágenes que habitan, sin orden, en la subjetividad-, escribe Hegel: «Esa noche uno la percibe cuando mira al hombre a los ojos -entonces se ve una noche que se hace espan- 
tosa-; aquí os cae encima la noche del mundo\%. El filósofo añadió al margen: "Poder de hacer salir de esa noche a las imágenes o [más bien] dejarlas abismarse en ellas (PHE II, 195; GW 8, 180-81).

En el magnífico estudio que precede a su traducción de la Filosofía del espíritu II, Taminiaux, tras acusar insistentemente a Hegel de bloquear la autonomía de la conciencia individual, reconoce refiriéndose al pasaje que hemos comentado: «En un solo momento parece que Hegel advierte esa irreductibilidad (de la Jemeinigkeit)", hasta el punto de considerar ese pasaje como «incongruente con el contexto» ${ }^{95}$.

La subjetividad humana encierra una ambigüedad terrible - encrucijada de la libertad y autonomía de la conciencia individual - : puede resurgir o, más bien, perecer. La voluntad es agente de un proceso y un trabajo que puede frustrarse. En el autoengendramiento del espíritu, el proceso puede detenerse en cualquier nivel. El hombre puede optar por la irracionalidad, aun estando dotado de racionalidad. El énfasis debe recaer no en el hecho de que, como en el Concepto, también en cl hombre ocurre la superación de ese momento, sino en que esa situación de bifurcación es constitutiva del hombre: el abismo se refiere a la posibilidad de lo bueno y de lo malo: «O bien el hombre edifica su mundo de acuerdo con formas de universalidad moral y política, o bien se hunde en el egoísmo de su particularidad... El hombre no depende más que de él mismo, es decir, de su razón y de las formas de sociabilidad que se da... No es algo dado de una vez por todas... El abismo que forma parte de su ser no desaparece de su horizonte, 96.

c) Finalmente, incluso en las obras más importantes de la madurez, individuo y Estado, moralidad y eticidad son, para Hegel, interdependientes.

i) Leamos el epígrafe $\$ 260$ de los Principios, que establece la interdependen- cia de Estado e individuo y que comienza así: «El Estado es la realidad efectiva de la libertad concreta» (PPD\& 260, 264; W7, 406), queriendo decir «concreta» que se opone a la mera dectaración formal de los derechos y requiriendo dos condiciones esenciales, que resume y explica Fleischmann: «Se requieren, en primer lugar, la libertad y los derechos del individuo de llevar una vida privada (familia) y de ejercer una profesión libremente escogida (colectividad). Pero, de otro lado, es necesario también que cl individuo reconozca al Estado. Esto implica, ante todo, que no sienta [experimente] los intereses del Estado como diametralmente opuestos a los suyos. Sabemos ya que para Hegel el interés subjetivo es el principio motor de toda acción de orden "moral" universal: según él la iniciativa individual no debe ser ahogada, y la participación en los asuntos públicos debe ser fomentada». Por otro lado, hay que reconocer que «el Estado es también verdaderamente el ámbito de las satisfacciones individuales... Es necesario, por tanto, que el individuo sienta que el Estado le necesita, que es esencial su contribución» ${ }^{97}$.

La síntesis hegeliana podría enunciarse así: «EI principio de los Estados modernos tiene la enorme fuerza y profundidad de dejar que el principio de la subjetividad se perfeccione hasta llegar al extremo independiente de la particularidad personal para, al mismo tiempo, retrotraerlo a su unidad sustancial, conservando así a ésta en aquel principio mismo" (PPD \& 260, 264; $W 7,407)$. Hegel añade: «Lo universal tiene, pues, que ser activo, pero, por otro lado, la subjetividad debe desarrollarse en forma completa y viviente. Sólo si ambos momentos se afirman en su fuerza puede considerarse que el Estado está articulado y verdaderamente organizado* (PPD $\$ 260$ Agr., 264; $W 7,407)$. Y también: «El interés particular no debe ser dejado de lado o reprimido, sino que debe ser puesto en concordancia con to universal, con to cual 
se conserva él mismo y [también] lo universal» ( $P P D \$ 261$ Obs., 266; W 7, 409).

La Enciclopedia explica así las tareas del Estado: «Su trabajo consiste en una relación con el extremo de la singularidad como conjunto de los individuos, en dos sentidos: en primer lugar, ha de conservarlos como personas, haciendo de su derecho una realidad necesaria y favoreciendo su bien - bien que es buscado por cada uno para sí mismo, pero que posee asimismo una dimensión universal-, o sea, el Estado debe proteger a la familia y dirigir a la sociedad civil; en segundo lugar, ha de hacer converger hacia la voluntad sustancial el derecho y el bien [de los individuos] y todas las disposiciones de espíritu y actividades del individuo, que tiende a constituirse en centro, y dominar [así] cualquier resistencia de esas esferas subordinadas manteniéndolas en la unidad inmanente y sustancial» $(E \$ 537,453 ; W 10,330-31)$.

El Estado representa la moral realizada, la plena identificación de los derechos y de los deberes. En un Estado bien ordenado, el deber no significa renuncia a la propia libertad - la obediencia que exige el Estado para el equilibrio de la comunidad se contrapesa con los derechos individuales-: «Los individuos tienen deberes respecto del Estado en la misma medida en que tienen tambiên derechos sobre el Estado" ( $P P D \$ 261,265 ; W 7,408$ ). De otra manera: «Deber y derecho forman unidad... El hombre tiene derechos en la medida en que tiene deberes y [tiene] deberes en la medida en que tiene derechos (Der Mensch hat insofern Rechte, als er Pflichten, und Pfichten, insofem er Rechte hat)» (PPD \& 155, 197; $\boldsymbol{W} 7,304$ ). Con esa compensación y ese equilibrio, los ciudadanos obtienen la satisfacción. Tiene razón Fleischmann: de acuerdo con Hegel, «el ciudadano esclavo del Estado, que cxiste para el Estado, no puede tener lugar en el mundo moderno», cuyo rasgo esencial -el valor del individuo- percibió Hegel como nadie. De ahí que «no sea por la opresión del individuo como el Estado alcanza su fin, sino únicamente por su satisfacción "del individuo" ". La libertad personal del ciudadano no se logra - aunque se prepara - en la sociedad civil. «La duración del Estado dependerá necesariamente de su fidelidad o de su infidelidad a su propia vocación de garantizar la libertad»; y su vocación consiste en una aactividad continuada al servicio de la libertad $\%$.

Fleischmann resume así el problema: "Frente a la familia (intimidad) y la sociedad civil (libertad individual, libre albedrio) el Estado parece revestir un carácter de coacción exterior (äusserliche Notwendigkeit). Pero este cuadro autoritario no es para el Estado un fin en sí. Él no puede tener autoridad y coacción por esencia; su fucrza reposa sobre el hecho de que pucde aportar al individuo satisfacciones desconocidas de la vida privada, y sobre todo el sentimiento de la utilidad pública»" ${ }^{99}$.

ii) Una de las cuestiones por las que más ataques ha recibido Hegel se relaciona con el institucionalismo. Hay que hacer justicia a Hegel en dos cuestiones.

Por un lado, hay que rescatar su concepción de la voluntad, expuesta al comienzo de los Principios de la filosofía del Derecho: en una interacción dialéctica, los contenidos del querer adquieren sentido por la intervención formal de la universalidad; en tal sentido, «la singularidad deja de ser un modo de ser y actuar inefable e incomunicable; por su constitución dialéctica, conjuga el sentido y la individualidad", por tanto-concluye Ricoeur-, upensar la singularidad como individualidad con sentido me parece una de las más innegables adquisiciones que una reconstrucción del concepto de razón práctica debe incorporar» ${ }^{100}$.

Por otro lado, frente a Kant que deja a la voluntad en wa idea vacia de ley general", con el peligro de cacr en la arbitrariedad, Hegel «sujeta» a la voluntad mediante las mediaciones concretas cons- 
tituidas por «las estructuras sucesivas del orden familiar, económico y político\%. Esta Sittlichkeit que se apoya en la moralidad y la redime con la incorporación de las instituciones «constituye el verdadero concepto de razón práctica» ${ }^{101}$. Y el interés de este planteamiento crece si percibimos, en él, una recuperación, «con los recursos del pensamiento moderno», del planteamiento aristotélico: «El bien del hombre y la tarea ofunción del hombre - esos conceptos tan preciosos del libro I de la Ética a Nicómaco- sólo se realizan completamente en la comunidad de los ciudadanos». Pero, de acuerdo con el mundo moderno, en la ley que gobierna a la comunidad debe encontrar el individuo «sentido y satisfacción»: la voluntad de cada uno se reconoce en la voluntad comunitaria. Ricoeur va más lejos: «La idea que [Hege]] propone, a saber, [que] la acción [individual] se dota de sentido en y por la vida política, no ha sido desplazada e incluso, de alguna manera, no ha sido todavía alcanzadas ${ }^{102}$. No ha sido todavía alcanzada porque el Estado que nos propone Hegel posee «forma incoactiva y tendencial». Es verdad que los hechos de la vida contemporánea lo desmienten cada día más: se tiende a una libertad liberada de las instituciones, consideradas coaccionantes y represivas. No obstante, Hegel seguiría teniendo razón; olvidamos «la terrible ecuación cstablecida por Hegel en el capitulo sobre el Terror en la Fenomenología del Espiritu: la ecuación entre la libertad y la muerte cuando ninguna institución mediatiza la libertad. El divorcio entre libertad e institución, si fuese durable, marcaria la más grande negación de la idea de razón práctica» ${ }^{103}$. El formalismo kantiano recibe un mazazo, que Findlay describe de la siguiente manera: «Hegcl ve en la imparcialidad positiva del Imperativo categórico una mera transformación de la negativa imparcialidad mortal de la guillotina» ${ }^{104}$.
La voluntad scrá auténticamcnte libre, si incorpora a su actividad la mediación de las instituciones y del Estado. La búsqueda del término medio como conciliación de los extremos es una de las mejores claves para comprender a Hegel. Su proyecto puede resumirse en el intento por evitar los extremos del mercado (Hobbes) y de la virtud ciudadana (Robespierre) ${ }^{105}$. Esa mediación apaciguadora es ejercida, de acuerdo con el derecho, por las instituciones universalmente reconocidas. Los conflictos no desaparecen, pero son arbitrados. Los extremos son violentos: la violencia política - que tiene en Hegel a uno de sus mejores intérpretes tós _ es evitada por la mediación. Como comenta Fleischmann, «estas consideraciones constituyen ya una banalidad que aturde, pero ise ha inventado algo mejor en nuestros dias? ${ }^{107}$.

Lo mismo hay que decir de la sustitución del voto censitario y universal (de carácter atomizado y abstracto -en sentido hegeliano-) por una representación por grupos profesionales de la sociedad civil, de acuerdo con su organización díferenciada: se trata de «una representación orgânica de los intereses de los ciudadanos», según Michel Jacob, quien argumenta con razón: «Examinado de cerca, ¿no es así como funcionan de hecho los países más avanzados en nuestros dias?: funto al sistema parlamentario, entran en juego las asociaciones profesionales, sindicatos obreros, campesinos, patronos, ctc., ejerciendo una fuerza mayor que la de los simples diputados ${ }^{108}$.

Por eso Ricoeur invita a olvidar los «argumentos políticos que denuncian en Hegel un apologeta del Estado represivo, 0 sea, un defensor del totalitarismo ${ }^{109}$. Ni la idea de la apropiación de Hegel por los nazis, ni la acusación de afinidad de Hegel con el nazismo lanzada desde el liberalismo y liderada por Karl Popper, tienen hoy justificación. En tal sentido, Habermas ha observado que «ambas interpretaciones, formas distintas de interpretar la mis- 
ma melodía, ya han sido contradichas [refutadas] enérgicamente por Marcuse y Ritter. El Hegel que se opone a la consumación terrorista de la Revolución burguesa, pero nunca a sus ideales, el Hegel que dcfiende los principios históricamente progresistas del derccho natural racional tan vehementemente contra los nuevos Ultras como contra los nuevos franconjanos, este Hegel diff́cilmente puede ser considerado como el causante de Carl Schmitt o de Binder, Larenz y otros" 110.

iii) En relación con este problema, Domenico Losurdo ha realizado una labor muy interesante y muy amplia. En una de sus obras estudia la recepción de Hegel en Europa, especialmente en Alcmania. Con una precisión admirable Losurdo desmonta el mito en que devino la acusación de Popper al pensamiento hegeliano de ser una fuente directa del nazismo alemán. Se nos explica de manera convincente cómo pudo producirse tal atribución, porque no existe nada más diametralmente opuesto al nazismo que la filosofia política de Hegel, hasta el punto de que, como escribe el autor, «Schmitt tenía razón al hacer coincidir la muerte de la filosofía hegeliana y del "Estado de funcionarios hegelianos" con la Machtübernahme de Hitler" "11, citando a continuación estas palabras del propio Schmitt: «Ese día [30 de enero de 1933] Hegel, por así decirlo, ha muerto» 112 .

2. Estudicmos ahora si es cierto que, en la obra de Hegel, no hay lugar para el ejercicio de la capacidad crítica y protestataria.

a) Debemos señalar que tampoco esta objeción vale en relación con los escritos juveniles, en los que, como vimos, la actividad comunicativa implica el diálogo.

b) Pero -incluso en la etapa de madurez - no es cierto que Hegel no acoja la crítica y la protesta. El filósofo distingue, en los Principios, dos conflictos entre la conciencia moral y el derecho ${ }^{113}$.
Uno se refiere a la rebelión de la conciencia moral defendiendo unos intereses privados frente a la universalidad del derecho; en este conflicto, Hegel descalifica a la conciencia moral.

Pero el filósofo alude a otro conflicto, ahora entre la conciencia moral de una victima de la miseria extrema y el derecho; en este conflicto, Hegel justifica la rebelión y la xilegalidad» de la primera contra el segundo: sc trata de las situaciones de «miseria" ( $P P D \$ 128,166 ; W 7,241$ ), como *el robo de pan que puede prolongar la vida»: aunque aconstituye manifiestamente un atentado a la propiedad de un hombre, sería injusto considerar esta acción como un robo ordinario. Si no se le permitiera a este hombre, cuya vida peligra, actuar así, se le consideraría como privado de derechos, y se le negaría su libertad al negarle su derecho a vivir» (PPD $\$ 127$, Agr., 166; $W 7,240-41$ ). Existe aquí «el derecho de exigir no ser enteramente sacrificado al derecho» (PPD \$ 127, Agr., 167; $W 7,241$ ): iinteresante juego de palabras! Al pobre de extrema necesidad le asiste el derecho de la contestación; adviértase: «derecho» y no mera concesión. Frente a la injusticia cometida por la conciencia marginada -lesión de la propiedad-, se cometería otra injusticia mayor, precisamente, la total negación 'de la existencia de su libertad. Hegel acoge, en su articulación, aparentemente tan rígida, la validez de la rebelión de la conciencia moral frente al hambre y miseria. Comenta Losurdo: «Queda uno desconcertado al encontrar esta declaración en un teórico de la objetividad de las instituciones; ${ }^{114}$.

El mismo problema puede ser considerado desde la perspectiva social. Hegel ha escrito, con este motivo, páginas memorables. En ellas nos habla de «la caida de una gran masa [de hombres] por debajo de un cierto nivel mínimo de subsistencia», lo que facilita el «que se encuentren en pocas manos riquezas desproporcionadas» (PPD $\$ 244,251 ; W 7,389$ ). La lógica del 
«sistema de las necesidades» provoca una acumulación de riquezas en pocos y una masa de pobres (PPD $\$ 243,250-51 ; W 7$, 389).

Los individuos son arrancados a la familia por la sociedad civil, pero al menos para convertirlos en hijos suyos - xhjjos de la sociedad civils (PPD $\$ 238,249 ; W 7$, 386)--; pero los pobres son arrojados de la sociedad civil, no son reconocidos como hijos suyos: son condenados a la miseria y a la angustia. Estamos ante una clase social; no se trata de un estamento: éste salvaguarda el interés común -relacionándose, por un lado, con la determinación sustancial de la familia y, por el otro, con la determinación racional del Estado-.

Cuando la clase social de los pobres interioriza esa humillación y sicnte indignación frente a tamaña injusticia, se rebela contra «la situación miserable a que es condenada y por la que es privada de aquel bien-estar que sería la condición de su satisfacción y de su consentimiento al orden común» 115. Es entonces cuando adopta la revuelta, deviniendo populacho -plebe (Pöbel)—, como explica el mismo Hegel: «La miseria en sí misma no conviene a nadie en plebe; ésta aparce sólo con la disposición de espíritu que se asocia a la miseria, a saber, la rebelión contra los ricos, la sociedad, el gobierno... Es así como se produce en la plebe ese mal que consiste en no creer en el honor de asegurarse su subsistencia gracias a su trabajo $y$, sin embargo, creer que debe tener asegurada su subsistencia como un derecho. Contra la naturaleza ningún hombre puede afirmar un derecho, pero en el estado de sociedad la indigencia adquiere la forma de una injusticia de la que es víctima tal o cual clase social (dieser oder jener Klasse). La importante cuestión de saber cómo se puede remediar la pobreza es un problema que agita y atormenta a las sociedades modernas» ( $P P D \& 244$, Agr., 251; $W 7$, $389-90)^{116}$.
Losurdo, comentando ese pasaje, ha explicado el sentido profundo de la rebeliôn: «La contestación objetiva que ejerce [provoca] la miseria extrema frente a lo que Hegel define como "derecho formal" cuestiona un contenido determinado, y lo cuestiona cn nombre de la reivindicación [exigencia] de una clase social de participar en la comunidad ética de la que ha sido excluida por un orden político-social determinado; se trata, por tanto, de una contestación que expresa no el rechazo de la ley y de la universalidad en cuanto tales, sino al contrario la exigencia de una universalidad más rica, de leyes e instituciones más ricas 117.

No se trata de defender la esfera privada frente a la objetividad pública, sino de parficipar en la universalidad ética. De ahí que Hegel, que siempre ha criticado el «bienestar» reclamado como exigencia privada, no dude en defenderlo, cuando forma parte del contenido de la ley y de las instituciones, en la parte dedicada a la sociedad civil: se trata de «que el bienestar particular sea tratado como derecho y [sea] realizado» (PPD \$230, 246;W7,382). No se trata de defender a la conciencia moral frente a la eticidad. Diríase que Hegel defiende siempre a la eticidad, pero de diferente manera - según el caso-: en el primer conflicto, descalificando a la conciencia moral; en el segundo - que acabamos de examinar-, la conciencia moral es aceptada como demanda de una eticidad más rica, capaz de evitar las desigualdades. Losurdo insiste: «Segün el punto de vista de Hegel, todavía válido, la seriedad y la sinceridad de esa angustia moral se justifican en la medida en que coinciden con el esfuerzo por realizar una nueva situación ética en el seno de la cual apelar a la buena voluntad y a la conciencia moral del individuo resulte superfluo o represente sólo un interés secundarios ${ }^{118}$.

III. Pensemos que las observaciones anteriores no permiten afirmar, a pesar de 
las oportunas dificultades planteadas por Gadamer, Ricoeur, Tugendhat, ctc., que todavía necesitamos a Hegel — como decía Kolakowski de Kant- ${ }^{119}$.

Quizá la actitud correcta no consista ni en renunciar a Hegel-perdiéndols-, ni en asumirlo - repitiéndolo, con evidente anacronismo-, sino en suprimirlo y conservarlo a la vez, utilizando su método mismo. Eric Weil es considerado como modelo de la manera en que debemos enfrentarnos a Hegel para atribuirle vigencia: comprenderle de diferente modo a como él mismo se comprendió ${ }^{120}$. Lo que afirma Castoriadis de la democracia griega, al compararla con la moderna, podríamos afirmarlo nosotros de Hegel: es «un germen, no un modelo» ${ }^{121}$. En tal sentido, en el campo de la política Hegel constituye, en palabras de Châtelet, "una referencia indispensable; no, como había soñado Hegel, en cuanto su política sabe y concluye, sino porque en ella se imponen con fuerza cuestiones que nuestras sociedades no resuelven más que con sangre y ruinas, y porque en ella se esbozan soluciones esenciales y discutibles» ${ }^{122}$.

Desde esa posición ya no tendría sentido argumentar que las observaciones $y$ sugestiones de Hegel quedan invalidadas, en su raíz, por su mistificación especulativa, por su idealismo. Tendría sentido si adoptáramos a Hegel como un modelo, lo que no es el caso.

Podemos aludir a varios puntos que lo confirman:

1. Por un lado, Hegel, en su escrito sobre Fichte y Schelling, procede a una refutación del Estado racional fichtcano con observaciones que limitan con nuestra problemática más reciente: tal Estado es incompatible con el mantenimiento de la libertad individual. Todo el nervio de la argumentación alude al carácter mecánico - no vivo- del Estado racional fichteano, que realmente no está inspirado por la razón, sino por el entendimiento: «Este
Estado-entendimiento no es una organización, sino una máquina; el pueblo no es el cuerpo orgánico de una vida común y rica, sino una pluralidad atomizada y enfermiza... Fint justitia, pereat mundus es la ley, no ya en el sentido en que Kant to ha enunciado: que llegue el derecho aunque perezcan todos los canallas del mundo, sino en el sentido de que el derecho tiene que Ilegar, aunque al punto sean extirpados de raíz la confianza, el gozo, el amor y todas las potencias de una identidad auténticamente ética» (DFSCH 102 y $103 ; W 2,87$ ).

Y en La consitución de Alemania escribe en el mismo sentido: «Existe un perjuicio fundamental según el cual el Fstado es una máquina de un solo resorte que comunica su movimiento a infinidad dc otros mecanismos» ( $E P 50 ; W 1,481)$; en ese Estado la economía queda totalmente controlada y planificada: los ciudadanos deben producir y consumir de acuerdo con las normas del Estado. La «máquina jerárquica» hace que los ciudadanos se sientan inútiles y sin dignidad ( $E P 52-3 ; W 1,482$ ). Por el contrario, según Hegel, el Estado debe confiar a la iniciativa de los ciudadanos todo lo que no se relacione con su seguridad exterior e interior, dejando en sus manos «el poder de organización y gestiơn» de la economía. Más aún: «Esta libertad es en sí misma sagrada, aunque no obtuviera resultados útiles» (EP $51 ; W 1$, 482).

Por otro lado, debemos tener en cuenta - Manfred Riedel lo senaló de forma definitiva - que Hegel incorpora a la filosofia política la categoría, antes desconocida, de sociedad civil como realidad distinta y opuesta al Estado: «La sociedad civil es la diferencia que se sitúa entre la familia y el Estado» $(P P D \$ 182$ Agr., $214 ; W 7$, 339). La actividad productiva y las relaciones y funciones económicas se sitúan fuera de la familia y al margen del Estado. Como advierte Riedel, se trata de «una sociedad despolitizada y fundamentada 
sobre la libertad y la igualdad de los individuos, cuyo centro de gravitación se traslada, con la revolución industrial de Ingla* terra, de la forma política de organización a la economía» ${ }^{123}$. El mismo comentarista añade en otro lugar: «Lo que Hegel con el término "sociedad civil" llevó a la conciencia de su tiempo no fue otra cosa que el resultado de la revolución moderna: la formación de una sociedad despolitizada mediante la concentración de la política en el Estado, fuera principesco o fuera revolucionario, y [mediante] el desplazamiento de su centro de gravedad a la economía... Fue gracias a ese proceso que fueron separadas por primera vez, en el interior de la sociedad europea, las condiciones civiles y las políticas, condiciones que, en el pasado, significaron una y la misma cosa - "communitas civilis sive politica", según Tomás de Aquino; "sociedad civil o política", según Locke-” ${ }^{124}$. Desde Aristóteles hasta Kant, incluyéndo a Hobbes y Locke, "civil» fue sinónimo de «político». La "sociedad civils hegeliana constituye así «la más audaz innovación después del concepto de "soberanía" de Bodin y del de "voluntad general" de Rousseau» ${ }^{125}$. A tal hallazgo contribuyó, sin duda alguna, su conocimiento de la economía política de Ricardo, Say, Smith y Stewart.

Hardimon, confirmando a Riedel, explica que la sociedad civil hegeliana significa «la emergencia de una nueva configuración social: una esfera social separada, privada, en la cual los agentes viven para sí mismos sin participar en los asuntos políticos. El núcleo de esa nueva esfera es la moderna economía de mercado. Su nueva forma de vida - la del burgués como opuesta a la del ciudadano- fue promovida por la naturaleza de las relaciones económicas capitalistas», por «el desarrollo del capitalismo, el comienzo del industrialismo y el ascenso de la burguesías ${ }^{126}$. La comprensión de tal fenómeno nuevo convierte a Hegel en «el verdadero creador de la teoria de la sociedad civils; por ello, es correcto afirmar que «la teoría hegeliana de la sociedad civil permanece como una contribución incontestable en la interpretación del mundo social» 127 .

Hasta podría decirse que Hegel con el concepto de «sociedad civil» introduce un neologismo en cuanto al contenido ${ }^{128}$ : pertenece a la Filosofia del Derecho, cuyo $\$ 182$ consagra la «destradicionalización» $129 \mathrm{del}$ concepto de usociedad civil». Conclusión: «No es casualidad que la discusión sobre la relación entre libertad, derecho y Estado sobre la base de una sociedad "en si" emancipada de un dominio político haya comenzado con Hegel; la dilucidación de esa relación es hoy más urgente que nunca» ${ }^{130}$.

a) Pues bien, Hegel rechaza la planificación estatal de la actividad económica de la sociedad civil. Henri Denis, que ha dedicado gran atención a esta cuestión, no duda en afirmar: «La crítica hecha por Hegel a la economía intrinsecamente planificada conserva en nuestros días toda su fuerza. La validez de esta crítica no depende de la cuestión de saber si el filósofo ha imaginado o no la generalización de la producción capitalista. La refutación hegeliana de las tesis de Fichte se funda en una exigencia que presenta a sus ojos un carácter absoluto: los individuos tienen que ser libres y no pueden serlo si el Estado decide soberanamente sobre el género de trabajo que afecta a cada uno y sobre la naturaleza de las tareas que han de cumplir ${ }^{131}$. La trágica experiencia del Este prueba el acierto de Hegel. Existen lagunas que hacen que su concepción de la sociedad civil quede sobrepasada en nuestros dias, ya que su racionalidad se basa en los estamentos y las corporaciones; se trata de una sociedad artesanal más que de una sociedad industrial. Pero esas lagunas pueden ser subsanadas recurriendo al propio Hegel, recurricndo no a los contenidos del sistema, sino al método dialéctico. 
b) Hegel nos aporta otra lección frente a cierto marxismo que prevé y anuncia la desaparición del capitalismo: nada menos hegeliano que pensar que las contradicciones acabarán destruyendo al capitalismo; la contradicción es la característica más importante de lo que es vivo: «Algo es viviente sólo cuando contiene en sí la contradicción y justamente [lo vivo] es esta fuerza de contener y sostener en sí la contradicción» $(L 387 ; W 6,76)$.

La experiencia ha demostrado que no está en el poder del hombre sustituir lo vivo por lo mecánico y por lo muerto. Los comunismos del Este lo intentaron y ya conocemos los resultados. El sistema de las necesidades posee rasgos de entidad viva: «El diagnóstico de Hegel es perfectamente justo. Si el Estado es el responsable único de la producción y de la distribución de los bienes no tolerará que los ciudadanos contesten sus decisiones y les prohibirá el libre uso de los diversos medios de expresión" ${ }^{132}$. En tales sociedades no existen ni Jibertad sindical (organizaciones obreras), ni libertad fuera del ámbito del trabajo. «Suprimiendo el capital privado se destruye toda posibilidad para la sociedad civil de constituirse y vivir frente al Estado. El resultado que se ha obtenido [países del socialismo real] confirma enteramente el juicio de Hegel según el cual sin una oposición de la sociedad civil y del Estado no es posible la libertad» ${ }^{133}$. Por tanto, «la planificación integral se revela incompatible con el mantenimiento de las libertades individuales; cuestión que, sin embargo, está hoy en el centro de la ciencia de la sociedad» 134 .

c) Entonces, Lqué decir de la supuesta divinización del Estado atribuida a Hegel? El éxito, entre los críticos de Hegel, de la expresión «lo divino sobre la tierra» para referirse al Estado está en proporción a su incomprensión - como apunta Catherine Colliot-Thélène- ${ }^{135}$. El texto hegeliano dice: Es ist der Gang Gottes in der Welt, dass der Staat ist, que deberia tra- ducirse: "Pertenece al modo de incidir Dios en el mundo el que el Estado exista» (PPD $\$ 258$ Agr., 260; W 7, 403). Segün Colliot-Thélènc, no sc trata de ala deificación de una realidad mundana, es decir, su transposición a un elemento heterogéneo que le conferiría su sentido últimos, sino de algo inverso: «la demanda dirigida a los creyentes de mirar dónde está la única efectividad verdadera, a saber, en las instituciones que organizan la vida colectiva», pues «nada hay más extraño a Hegel que reclamar a la creencia las claves del sentido de la vida terrestre» ${ }^{136}$. En un sentido muy parecido explica Fleischmann el significado de la expresión wirklicher Gott o «Dios real» $(P P D \$ 258$ Agr., 260; W 7, 403): «La política ha realizado eficazmente lo que la religión no hacía más que imaginar y proyectar en el más allá» ${ }^{137}$.

El Estado así entendido se convierte en el símbolo de una razón que puede resolver los conflictos con que tropezamos en la conquista de la libertad. De acuerdo con estas reflexiones, nos explicamos lo que escribió Gans, discípulo de Hegel, sobre los Principios: "[Esta obra] está toda hecha del metal de la libertad» 138 . Hay que añadir que toda su obra está fabricada con ese metal de la libertad.

2. No por eso se convierte Hegel en defensor del liberalismo de los economistas franceses o ingleses. $Y$ asi, en el Sistema de la vida ética, nos advierte de los peligros de la libertad económica si se libra a sí sola: estariamos ante otro mecanismo ciego, ante otra máquina. El poder debe controlar esa desigualdad y destrucción que provoca el mercado dejado a sus fuerzas como laissez faire total; dispone para ello de elementos como los estamentos y las corporaciones.

Hegel reconoce la insuficiencia de los modelos antiguos - polis, cristianismo primitivo- para operar en el mundo moderno que descansa en el valor de la indjvidualidad. Pero Hegel ha visto asimismo 
las insuficiencias del Estado liberal que se limita a satisfacer los valores individuales. En esto último ha insistido Ilting: «Se comprenderá mal la significación de la concepción hegeliana del Estado mientras no esté claro que ella, en la teoría hegeliana del Estado moderno, ticne la función de subsanar el defecto manifiesto de la concepción liberal del Estado" ${ }^{139}$. Ante el énfasis de Hegel sobre la importancia decisiva de la totalidad deberíamos poder detectar lo que se esconde detrás: una crítica profunda -que todavía sigue teniendo fuerza y eficacia - de las insuficiencias del liberalismo.

Era natural que, en un contexto histórico y social caracterizado por el surgimiento de los totalitarismos fascista y comunista, un liberal como Karl Popper buscara antecedentes culpables y arremetiera contra Marx, Hegel y, más atrás, contra Platón ${ }^{140}$. Pero «podemos suponer que Hegel hubiera respondido en seguida que precisamente ćste cra cl problema: si puede el Estado moderno ser liberal y nada más». Ahora - después del contexto histórico de Popper-, «resulta claro que los problemas del Tercer Mundo no pueden ser resueltos con los medios de la política liberal. Esto confirma la visión de Hegel acerca de los límites del principio liberals ${ }^{141}$.

En esa dirección, Henri Denis va muy lejos: sugiere que Hegel podría ayudarnos a salir del capitalismo con una salida distinta de la propuesta por Marx. La sociedad civil hegeliana no coincide con la sociedad capitalista - en la que no tienen sentido los estamentos y corporaciones-. pero la dialéctica que lleva en aquélla a que los intereses contrapuestos de los estamentos y de las corporaciones puedan converger mediante un arbitraje puede realizar la misma función, en relación con las clases socialcs, en la sociedad capitalista. Podría parecer imposible esto último, pero esa imposibilidad se debería a la defensa a ultranza del lassez faire por parte de unos o por parte de otros, a la idea de que los conflictos exigen una revolución. La dialéctica podría introducir la vida ética en ambas sociedades - sociedad civil hegeliana y sociedad capitalista- ${ }^{142}$.

3. Ni puro homo socialisticus - $\sin$ intereses personales-, ni puro homo oeconomicus -que sólo atiende intereses individuales- ${ }^{143}$. Hegel cuestiona el derecho y la moral de la modernidad - que surge con Hobbes - por la insuficiencia de los planteamientos individualistas liberales, y recurre a la antiguiedad griega - Platón y Aristóteles- - para corregir el individualismo con la comunidad institucionalizada, pero también cuestiona a los gricgos confrontados con el ideal moderno - que ha descubierto la individualidad, $\sin$ cuyo valor no se puede construir ninguna teoría política- Realmente aspira a una sintesis de ambas tendencias.

Los derechos del individuo (derechos-libertades) constituyen el legado de la tradición liberal desde Locke; los derechos relacionados con la justicia, la perspectiva de la totalidad y la intervención estatal (derechos-créditos) representan el legado de la tradición socialista. Los liberales han ignorado $o$, al menos, infravalorado los derechos-créditos, los derechos sociales; los socialistas, al revés, han ignorado 0 , al menos, infravalorado los derechos-libertades. Unir esas dos tradiciones, armonizarlas, es una necesidad sentida por Hegel (y por nosotros todavía): «Esa síntesis está en el centro de la reflexión de Hegel» -afirma Pinson- ${ }^{144}$.

La tarea de toda filosofia política consiste hoy en la articulación, conciliación y sintesis de esas dos exigencias ineludibles. A la historia de la filosofía política corresponde estudiar cómo han resuelto esa síntesis los filósofos: en nuestro caso, estudiar cómo la ha resuelto Hegel.

Hegel nos ofrece una magnífica exposición de «el derecho de la particularidad del sujeto a encontrar su satisfacción $o$, lo que es lo mismo, el derecho de la libertad. 
subjetiva constituye el punto central y crítico que marca la diferencia entre los tiempos modernos y la antigüedad» (PPD \& 124 Obs, 163; $W 7,233)$. Hegel restablece la Sittlichkeit griega corrigiéndola con lo que la desiruyó: el espíritu del derecho, la persona y la propiedad. «iQué apuesta - $\mathrm{co-}$ menta D'Hont-: se trata para Hegel de fabricar una nueva Sittlichkeit utilizando como ingredientes lo que había corrompido y destruido la antigua: la propiedad, el atomismo (la atomización), la revuelta individual, la desviación criminal, el derechot» Se trata ahora de «una Sittlichkeit pasada por el Purgatorio del derecho y de la moralidad, de los que conserva lo esencial, tras suprimirlos y sobrepasar$\operatorname{los}_{2}{ }^{145}$. Y la Sittlichkeit culmina en el Estado.

La desaparición del socialismo real y el deterioro de la socialdemocracia no implican la desaparición de la exigencia de los derechos-créditos - resumidos en el valor de la justicia-, lo que implican es la búsqueda de otra fórmula para los derechos sociales, cuya exigencia mantiene Hegel. Acudir a él para patrocinar el triunfo definitivo de la democracia liberal $-\mathrm{y}$ un supuesto final de la historia-, como hace Fukuyama, es arrebatar a la síntesis hegeliana uno de los elementos que la constituyen, destruyéndola.

De ahí el interés de esta observación de Ilting: alos problemas que debian seguirse del nacimiento del proletariado industrial los anticipó con una expresión con visos de profética: "Por medio de esta dialéctica suya la sociedad civil es llevada más allá de sî" (\$246). Su filosofía política estaba justamente dispuesta para desarro* llar un socialismo libcral... [Pcro] Hegel no sacó las consecuencias que se siguen del planteamiento de su filosofia politicas ${ }^{146}$. Hegel debería haber ido en el sentido y dirccción de la síntesis entre libcralismo y socialismo. Ilting piensa que predomina, en la eticidad, la inspiración platónico-aristotélica ${ }^{147}$. En el mismo sentido se ha manifestado Claude Pinson: reconoce una dimensión lockiana en Hegel, pero añade: «Un liberalismo temperado por un holismo predominante» ${ }^{148}$.

Debemos reconocer que Hegel ha expresado de forma definitiva la exigencia, al menos, de una armonización entre liberalismo y socialismo. Quien ha señalado esto con más claridad ha sido Solange Mercier-Josa: «La lección hegeliana permanece viva para nosotros si la traducimos como la idea de que Europa sigue siendo un motor de desarrollo histórico en la lucha por un nuevo orden económico y político mundial que sea socialista y democrático. El socialismo democrático ino implica la conciliación de la libertad subjetiva y la voluntad sustancial? El universal concreto hegeliano, ino prefigura lo que hoy se reivindica con la expresión socialismo democrático? Intcrpretada así, y retomando la expresión de Ricoeur, la "metáfora" permanece "viva" "149.

Insistimos en que, a pesar de su impregnación idcalista, cl proyecto afecta de manera apasionante al hombre y a la sociedad de nuestros días. De ahí que nos parezca acertado este diagnóstico de Rosenfield: «La violencia de los acontecimientos históricos que han marcado a los siglos $\mathrm{XIX}$ $y \times x$ nos ha planteado de nuevo, con una agudeza acrecentada, la problemática a la que Hegel se esforzó en contestar: ¿́cómo organizar libremente las aportaciones del individuo y de la comunidad en el seno de un solo y único movimiento de mediación? Pensar en el individuo como miembro de una comunidad libre cs uno de los temas con que nos debatimos todavias 150 .

\section{Postscriptum}

Hemos estudiado los temas fundamentales de la filosofía política de Hegel en el contexto problemático de nuestro tiempo, reintroduciéndolos así en la historia, a la que podrían aportar más de una ayuda. 
Al finalizar este trabajo, su autor espera que, en el peor de los casos, se le acuse de «hegelitis", pero nunca de shegelianerías 151

\section{SIGLAS UTILIZADAS PARA LOS TÍTULOS DE OBRAS DE HEGEL}

CS: Creer y saber, trad. de Jorge Aurelio Díaz, Bogotá, Grupo Editorial Norma, 1992.

DN: Des manières de traiter scicntifiquement du droit naturel, traduction et notes par Bernard Bourgeois, París, Vrin, 1990.

DFSCH: Diferencia entre los sistemas de filosofia de Fichte y Schelling, trad. de Carmen Paredes, Madrid, Tecnos, 1990.

$\mathrm{E}$ : Encyclopédie des sciences philosophiques en abrégé (1830), traduit de l'allemand par Maurice de Gandillac sur le texte établi par Friedhelm Nicolin et Otto Pöggeler, París, Gallimard, 1970.

EP; Ecrits politiques, Michcl Jacob y Pierre Quillet (eds.), París, Champ Libre, 1977.

F: Fenomenología del espinitu, trad de Wenceslao Roces, México, FCE, 1966.
GW: Gesammelte Werke, Bd. 8, edición de la Rheinisch-Westfälische Akademie der Wissenschaften, Hamburg, Meiner, 1976.

L: Ciencia de la Lógica, trad, de Augusta y Rodolfo Mondolfo, Buenos Aires, Solar-Hachette, 1968.

LFH: Lecciones sobre la filosofia de la historia universal, trad. de José Gaos, México, Fondo de Cultura Económica, 1953.

LHF: Lecciones sobre historia de la filosofia, trad. de José Gaos, México, Fondo de Cultura Económica, 1977.

MB: Dass Magistrate von der Bürgern gewält verden müssen (1798), en Werke in zwanzig Bänden, Bd. 1, Frankfurt am Main, Suhrkamp Verlag, 1970.

PHE II: Jenaer Realphilosophie II, trad. al francês por Jacques Taminiaux: «Philosophie de l'esprit (1805-06)", en Naissance de la philosophie hégélienne de l'État, París, Payot, 1984.

PPD: Principes de la philosophie du droit ou droit naturel et science de l'État en abrégé, texte presenté, traduit et annoté par Robert Derathé, París, Vrin, 1989. W: Werke in zwanzig Bänden, Frankfurt am Main, Suhrkamp Verlag, 1970.
' Ernst Bloch, El pertsamiento de Hegel, Mćxico, Fondo de Cultura Económica, 1949, p. 8.

¿ La expresión pertenece a Paul Ricocur, Temps el récit, III, Purís, Seuil, 1983, p. 280.

* Ricoeur, op cit, p. 289.

- Hegel, Lecciones sobre la fllosofia de la historia thiveral 1 , «Introducción generals, trad. de Jose Gaos, México, Fondo de Cultura Económica, 1953 (en adelante y dentro del texio, $L F H M$ ).

Las referencias a los escritos de Hegel tendrán dable expresión: una primera para las traducciones -y ediciones aisladas-, con la sigla atribuida y la prágina, y otras para G. W. F. Hegel, Werke in zwanzig Bänden, Frankfurt am Main, Suhrkamp, 1970; $W$, con el volumen correspondiente y la página. Se exceptúa la Philosophie des Geistes (1805-06), Jenaer Rualphilosophie $I$, en Gesammelte Werke, Bd. 8 , edición de la Rhei-
nisch-Westfalische Akademie der Wissenschaften, Hamburg, Meinet, 1976, sc citará: $G W$. Utilizamos la traducción de Jacques Taminiaux, aPhilosophie de l'es" prit (1805-06)", en Naissance de la philosophie hégéIienne de l'Etal, Paris, Payot, 1984: PHE II.

s R. G. Collingwood, Idea de la historia, Méxjco, Fondo de Cultura Económica, 1965, p. 117. Cursivas del autor.

* H. Arendt, La vida del espiritu, Madrid, Centro de Estudios Constitucionales, 1984, p. 300.

- Ricoeur, op. cit, p. 282.

* Gadamer, Verdad y mérodo J, trad. de Ana Agud y Rafael de Agapito, Salamanca, Sigueme, 1993, p. 416. Como puede advertirse, hemos introducido algunos matices en la traducción.

Q Gadamer, op. cit. pp. 416 y 225.

16. Gadamer, ch. cit. p. 420 . 
1 Gadamer, op. cit, p. 415 .

12 Gadamer, op. cit, p. 417.

13 Gadamer, op. cit. p. 372. Cursiva del autor.

14 Gadamer, op cit, p. 415. Cursiva de] autor.

is Ricoeur, Temps el récit, op. cit, p. 299 , n. 1.

Ricoeur, op. cit., p. 298. Cutsivas nuestras.

17 Ricoeur, op. cit, p. 291. Cursiva del autor.

Ricocur, op, cit. p. 289. Cursiva del autor.

$19 \mathrm{X}$. Zubiri, Los problemas fundamentales de la metafisica occidental, Madrid, Alianza, 1994, p. 312.

20 Ricoeur, op. cit. pp. $298-99$.

"Zubiri traduce List como listeza, treta, añagaza. Cfr. op. cit., p. 114.

2 Ricoeur, op. cit., p. 287.

2 Hegel, Des manières de trater scientifumement du droit naturel, trad. et notes par Bernard Bourgeois, Paris, Vrin, 1990 (en adelante, $D N$ ). Los paréntesis son del traductor.

24 Marc Richir, Du sublime en politiquc, Paris, Payot, 1901, pp. 226-27.

25 Ricoeur, Du texte a laction. Essais d'hermêneninue II, Paris, Seuil, 1986, p, 255.

2* Ricoeur, op. sit, p. 282. Ricoeur, en otro lugar de la misma obra, ha estudiado detenidamente esa posibilidad de corregir a Hegel mediante Husserl. Partc, como antes, de la quinta Meditación cartesiana de Husserl, confrontada con el capitulo V1-«Espíritu»de ia Fenomenologia del expíritu. Pero considera necesario complementar el irascendentalismo de Husserl con los contenidos de la reflexión de Weber. Cfr. op. cit, pp. 299-301.

${ }^{7}$ Ricoeur, Du texte, op. cit., p. 257.

25 Ricoeur, Du texte, op. cit. p. 258.

${ }^{29}$ Ricoeur, Du texte, op. cit, p. 301.

3icocur, Du texte, op. cit, pp. 301-02.

3) Ricoeur, Dis texte, op. cit. p. 302.

12 Paul Ricoeur, Soi-mêne comme un aure, París, Seuil, 1990, p. 297.

3. Ricoeur, Soimmeme, op. cit, p. 397 , n. 3.

* Para las citas de los Principios de la filosofia det derecho utilizamos la traducción francesa de Robert Derathé, Principes de la philosophie du droil ou droit naturel et science de l'État en abrégé, Paris, Vrin, 1989 (en adelante, $P P D$ ). Tras la sigla va la página de Dexathé; a continuación, como de costumbre, el volumen y păgina de Werke.

Tuvimos que prescindir de la versión castellana de J. L. Vermal, Barcelona, Edhasa, 1988, que traduce siempre el habitual *an und für sich» hegeliano por uen si y por sf", mientras Derathe por wen soi et pour sojw y Carlos Diaz (Madrid, Libctarias/Prodhufi, 1993) *en sí y para sì, pero este bltimo, curiosamente, al agradecer su dıuda para con ella califica de «magistral» (p. 40, n. 23) la traducción de Vermal. También traducen correctamente - «en si y para sis- Alfredo Llanos (Bucnos Aires, Siglo XX, 1987) y Mues-Ceballos (México, Universidad Nacional Autónoma, 1985).
35 En $\$ 135$ Obs. $(173 ; W 7,253)$, Hegel remite a la critica expuesta en la Fenomenología y en la Enciclopedia.

35 Ricoeur, Soi mêne, op. cir, p. 397.

"Ricocur, Sol même, op. cir., pp. $296-98$.

3 Ricoeur, Soi mene, op. cit, p. 397.

*) Ricoeur, Soi mâme, op. cit, p. 298.

4o Ricoeur, Soi même, op. cit, ibid.

41 Ernst Tugendhat, Autoconciencia y aufodeterminación. Una interpretación lingitístico analitica, Madrid, Fondo de Cultura Económica, 1993.

42 Hegel, Lecciones sobre la historia de la filosofia, II, México, FCE, 1977 (en adelante, LHF III).

4. Tugendhat, Autoconciencia y autodeteminación, op. cir., pp. 34-35.

44 Hegel, Fenomenología del espürtu, trad de Wenceslao Roces, México, FCE, 1966, referida en el texto como $F$

45 Tugendhat, op cil, p. 10 .

46 Tugendhat, op. cit, p. 30.

47 Tugendhat, op, cit, p. 35 .

4 Citamos de acuerdo con la Encyclopédie des sciences philosophiques en abrégé (1830), traduit de lallemand par Maurice de Gandillac sur le texte ettabli par Friedhelm Nicolin et Otto Poggeler, Paris, Gallimard, $1970(E)$.

*9 Tugendhat, op cit, p. 272.

so Tugendhat, op. cit, p. 273.

31 Tugendhat, op. cit. p. 274.

52 Tugendhat, op. cit, p. 121.

5 Ricoeur, Temps et recit, op. cit, pp, 280, 293 y 298.90.

4. Vietzsche, El Gay Saber, $\$ 357$, trad. de Luis Jimenez Moreno, Madrid, Narcea, 1973, p. 378. Crr. Sämtliche Werke, bd 3, Colli-Montinari, Berlin, De Gruyter, 1980, p. 598.

ss Giuliano Marini, aEstructura y significados de la sociedad civil hegelianan, en Estudios sobre la \&Filosofia del Derechos de Hegel, Gabriel Amengual (ed.), Madrid, CEC, 1989, p. 247.

so Solange Mercier-Josa, Pour tire Hegel et Marx, París, Éditions Sociales, 1980, p. 16.

${ }^{37}$ Cfr. Heidegger, Ser y tiempo, \&82, trad. de José Gaos, México, Fondo de Cultura Econômica, 1962. pp. 461.69 .

* Catherine Malabou, «L'avenir de Hegel ou de la plasticité temporelle en dialectique», en Hegel aujourd'hui, P. Verstraeten (coord,), París, Vrin, 1995, p. 226. Se trata del resumen -comentado-- de su tesis, dirigida por Jacques Derrida y leida recientemente en París X-Nanterre.

59 Además de las matizaciones introducidas, hemos corregido arelieve» (trad. Roces) por «valors (carácter), de acuerdo con la traducción de J. Hyppolite, La phenomenologie de l'esprit, I, París, Aubier Montaigne, s/d, p. 55

(1) Malabou, opt cit, p. 226.

5 Malabou, op, cit., p. 232.

63 Malabou, op. cit, p. 227. 
${ }^{63}$ Koyté, Etudes dhistoire de la pensée philosophie, París, Vrin, 1961, p. 177. Kojève hará derivar la primacía del futuro en primacia de la muerte.

ot H. Arendt, op, cit, p. 300.

6. H. Arendt, op cit, p. 303 ; cfr, Koyré, op. cit, p. 189 ,

os Ricoeur, Temps et récit, op. cit., p. 293, n. 1.

b7 Jacques D'llondt, heget filósofo de la historia viviente, Buenos Aires, Amorrortu, 1971, p. 69 (segunda cursiva nuestra).

${ }^{3}$ D'Hondt, eLa personne et le droil abstrait selon Hegel $_{2,}$ cn Droit et liberté selon Hegel, Guy Planty-Bonjour (ed.), París, PUF, 1986, pp. 113-115 y 119.

Solange Mercier-Josa, Retour sur le jeune Mar. Deux éfutes stur le rapport de Marx à Heget, Paris, Méridiens Klincksieck 1986, pp. 179-180.

7 Collingwood, op. cit., p. 120.

7 Mercier-Josa, Pour lire Hegel et Marr, op cit, pp. 27-28. "Marx "desmetaforiza" a Hegels: la contradicción del espiritu consigo mismo es metátora de la lucha de clases. Lo universat en si y para sí es la socicdad sin clases, es la clase universal -expresión de la supresión de todas las clases- (Pour lire Hegel et $M a x$, op. cit, pp. 9 y 31 ). En otro lugar escribe la autora: «[La astucia de la razón] es una manera metafórica de pensar el proceso por el cual la historia se universaliza» (Retour sur le jeune Mar, op. cit., p. 131).

72 Habermas se ha ocupado de ello en algunas de sus obras. Así, en el Discurso de la modemidad (Madrid, Taurus, 1989) se ha fijado en los escritos de juventud -especialmente en los teológicos-de Hegel, mientras que en Ciencia y técnica como ideologia (Madrid, Tecnos, 1984) ha estudiado las huellas de ese planteamiento en los escritos de Jena - las dos filosofias del espiritu y ol Sistema de la vida ática-.

7. "La constitución de l'Allemagne", en Hegel, Ecrits politiques, Michel Jacob y Pierre Quillet (eds.), París, Champ Libre, 1977 (citado EP).

${ }_{74}$ aDas Magistrate won der Bürgern gewält verden müssen (1798)\%, en Werke in zwarzig Banden, op. cit., bd 1 , trad. nuestra (citado $M B$ )

${ }^{75}$ Habermas, Discurso, op. cis., p. 48.

${ }^{76}$ Habermas, Discurso, op. cit., pp. 43 y 44.

"Jean Wah], Etudes kierkegaardientes, París, Vrin, 1974 , pp. 151 y 154.

"Hahermas, Ciencias y fenicas, op. cit, p. 16.

Fabermas, Ciencias y técnicas, op cit., p. 18.

Hegel, Difcrencia entre los sistemas de fllosofia de Fichte y Schelling, trad. de Carmen Paredes, Madrid, Tecnos, 1990 (citado DFSCH).

61 Habermas, Discurso, op. cit., p. 46. Tal «autofundamentación» es explicada por Habermas en más de un pasaje: «La modernidad no puede ni quiere tomar sus criterios de orientación de modelos de otras épocas, tiene que extraer su normatividad de si misma... No tiene mas remedio que echar mano de sí misma. Esto explica la irritabilidad de su autocomprensión» (id, p. 18). «Justificación de la modernidad desde sí misma» (ibid.). "La t́poci moderna había cobrado con- ciencia de sí a través de una reflexión que prohibia todo recurso sistemático a las ejemplaridades del pasadow (p. 46).

82 Habermas, Discurso, op. cit. p. 38.

3* Marcel Mery, «Introductions, en IIegel, Premiares publicutions, Paris, Ophrys, 1975, p. 70.

84 Habermas, Discurso, op. cit., p. 89.

ss M. Mery, op, cit, p. 74.

sa Habermas, Discurso, op. cit, p. 35.

"Cr. Mario Rossi, De llegel a Marx, A. Hegel e to Stato, 1, La fomazione del pensiero de Megel, Milín, Feltrinelli, 1976, p. 172.

Esa tragedia está escrita en la Gran Lógica, que es una gramática linguística (Habermas, Discurso, up. cit., p. 45).

* Hcgel, Creer y suber, trad de Jorge Aurelio Díaz, Bogotá, Grupo Editorial Norma, 1992, p. 194 (citado CS).

Habermas, Discurso, op. cit, pp. 57 y 58.

91 Habermas, Teorta y praxis. Estudios de filosofia social, Madrid, Tecnos, 1987, p. 154.

92 Habermas, Discurso, op. cif. p. 57.

93 Hegel, Ciencia de la Lógica, trad. de Augusta y Rodolfo Mondolfo, Buenos Aires, SolarmHachette, 1968 (en adelante $L$ ).

$\$ 4$ Denis Rusenfield, Politica y libertad. La esmuchum Lógica de la "Filowofia del Derechos de Hegel, México, Fondo de Cultura, 1989, pp. 21-22.

95 Taminiaux, Naissance de la philosophie hégélienre de l'Erat, op. cit, p. 178.

\% Denis Rosenficld, Del mal. Ensayo para introducir en fliasofía el concepio del mal, México, FCE, 1993, pp. 171 y 172 .

"1) Eugène Fleischmann, La philosophie politique de Hezel sous forme d'un commentaire des Fondemenss de la philosophie du droit, Paris, Gallimard, 1992, p. 264.

Fleischmann, La philosophie politique de Hegel, op. cit., pp. 268 y 282.

*) Fleischmann, La philosophie politique de Hegel, op. cit., p. 266.

Ricoeur, Du texte à laction, op. cit, p. 253.

tw Ricoeur, Du tate à l'action, op. cit, pp. 253-54.

102 Ricoeur, Du texte à laction, op. cit., p. 254.

10 Ricocur, Du texte à l'action, op. cit., pp. 254-55.

in John Niemeyer Findlay, Reexamen de Hegel, Barcolona, Grijalbo, 1969, p. 125.

"steven Smith, kllegel's critique of Liberalismes, en American Political Science Review; 80 (121-139), p. 137. Cor. Renato Christi, Le liberalisme conservateur, París, E. Kimé, 1993, p. 197, n. 12.

10\% P. Quilet, «Notice" sobre "Actes de l'Assamblée des Etats du Royaume de Wurtemberg cu 1815 et 1816. Analyse critique", en Hegcl, Ecrits politiques, op. cit., p. 197.

107 Fleischmann, "Dialectique et conflit», en Hegel et la philosophie du droit, op. cit, p. 74.

las Jacob, wotice" sobre «A propos du "Reform bill" anglaism, en Hegel, Ecrits politiques, op. cit., p. 354. 10 Ricoeur, Du terte a laction, op. cit, p. 293, n. 1. 
It Habermas, Teoria y praxis, op. cit. p. 161.

"11 Losurdo, La catastrofe deila Germania e la inmagine di Kegel. Instituto Italiano per gli Studi Filosofici, 1987, que hemos leido en su traducción francesa Hegel et la catasirofe allemande, París, Albin Michel, 1994, p. 129.

Losurdo es un estudiaso de llegel al que ha defondido de las tradicionales - y ya tópicas - acusaciones do fascismo avant la letre. Cfr. Hegel, Marx e la tha dirione liberale, Roma, Editori Riuniti, 1988, y especialmente Hegel ef la carastmphe allemande, citada más arriba.

En otro lugar explica Losurdo cómo, a partir de 1848, el pensamiento de Hegel - de manera especial el ideal de la eticidad - es barrido del ámbito alemán y aencuentra asilo en un pais donde el proceso revo. lucionario simbolizado por el "Risorgimento" se encuentra cn plena expansion\%. Son los bermanos Spayenta, especialmente Bertrando, los que lo acogen como instrumento revolucionario. Su herencia será recogida por Antonio Labriola, que confesará, en carta (14-III-1894) a Engels: "Quiza -y sin quizá-- yo he devenido comunista debido a mi educación (rigurosamente) hegeliana ( $\alpha$ La révolution de 1848 : limage de Hegel en Italic et en Allemagne», en Rewue de Metaphysique, núm. 1, 1994, pp. 32-33).

l" Carl Schmitt, Staat, Bewegung, Volk, Hamburg. 1933, p. 32; Losurdo, op. cit. p. 129.

113 D. Losurdo, a'Tension morale et primat de la politique chez Hegelm, en Actuel Marx núm. 10 (Ethique et politique), 1991, p. 76.

"t Losurdo, "Tension morale", op cit, ibid.

IIs I.P. Lefehvre et P. Macherey, Hegel et la sociéts Paris, PUF, 1984, p. 45.

It Se anticipan aquí cuestiones analizadas por Marx y otros sociologos: la clase y la relación entre ser y conciencia de clase (Lefebve-Macherey, Hegel er ia socicte, op. cit., bid.).

in Losurdo, kTension morale", op. cit, pp. 77-78.

"1* Losurdo, «Tension morale", op. cit., p. 80.

114 Leszek Kolakowski, «Warum brauchen wir Kant?\%, Merkur, num. 9-10, 1981.

120 Gilbert Kirscher, "Hegel anjourd'hui?", Archives de Philosophie, núm. 47, 1984, p. 320.

121 Cornclius Castoriadis, Los dominios del hombre: las encrucijadas del labeninto, Barcelona, Gedisa, 1988, p. 99. Cursiva del autor.

12 Chátelet, Hegel, Principes de la philosophic du droit», en Dictionnaire des oeuwes politiques (sous la dircction de $\mathrm{F}$. Châtelet, $\mathrm{O}$. Duhamel. Evelyne Pisier), PUF, 1986, p. 318.

Z. A. Pelczynski afirma de manera semejante qua Hegel nos ayuda a tener consciencia del problema politico y wos proporciona el utillaje para afrontarlow, lo cual wno es una conquista sin valors [kThe significance of Hegel's separation of state and civil societys, en The state and civil society, Z. A. Pelczynski (ed.). Cambridge University Press, 1984, p. 13].
123 Manfred Riedel, dDialettica nelle istituzioni. Sulla struttura storica e sistematica della filosofia dcl diritto di Hegels, en VV, Filosofia e societa in Hegel, Trento, Verifiche, 1977, p. 50.

124 M. Ricdcl, «ll concetto di "società civile" e il problema della sua origine storican, en Hegel fra tradizione e rivoluzione, Roma-Bari, Laterza, 1975, $\mathrm{pp}, 142-43$.

125 Z. A. Pelczynski, "The significance of Hegel's separation of the state and civil society», cr The Stute and Civil Society, Z. A. Pelczynski (ed.), Cambridge University Press, 1984, p. 4.

${ }^{126}$ Michael Hardimon, Heget's Social Philosphy. The Project of Reconciliation, Cambridge University Press, 1994, pp. $189-190$.

${ }_{27}$ Maspetiol, Esprit objectif et sociologie héglienne, París, Vrin, 1983, p. 104.

13 Ricdel, «ll concetto di "socictà civile" e il prom blema della sua origine storica $\%$, op. cit, p. 126 .

12 Riedel, «Il concetto di "società civile" e il problema della sua origine storican, op. cit., p. 143.

1. Riedel, aDialettica nelle istituzionim, op. cit. p. 60 .

"Henri Denis, Logique hégêlienne et systèmes économiques, París, PUF, 1984, p. 34.

1.2 Denis, Logique hegelterne, op. cit., p. 159.

1.3 Denis, Logique hégélienne, op. cit., pp. 160-61.

13 Denis, Logique hégélienne, op. cit, p. 152.

135 Catherine Colliot-Thelène, Le dósenchantoment de l'État. De Hegel à Max Weber, Paris, Ed. de Minuit, 1992, p. 62.

ins Colliot-Thelene, op. cit, p. 63.

13 Ficischmann, op. cit., p. 258.

138 Eduard Gans, en Vomorf zur Rechtsphilosophie, SW (Sämtliche Werke), 7, Frommann. Stuttgart, Jubiläunausgabe, pp. 6-7. Cfr. Planty-Bonjour, Le projet hegelien, op cit, p. 123, y E. Weil, Hegel y el Estado, op. cit., p. 71 .

139 Karl-IIeinz Ilting, «La estructura de la Filosofia del Derecho de Hegel», on Estudios sobre la Filosofia dol Derechon de Hegel, op. cit., p. 83.

th Benseuld ha parodiado el título de una famosa obra de Popper - Miseria del historicismo- con estos términos: emiserias del popperismo" (Marx l'intempesif, Paris, Fayard, 1996, p. 21).

14 Ilting, «La estructura", op. cit, pp. 91-92.

${ }^{142}$ II. Denis, aSociété civile hégélienne et capitalismen, en Droüt at libenté selon Hegel, Planty-Bonjour (ed.), op. cit.s, pp. 85-86.

${ }^{143}$ Denis, Logique hégélienne, op. cit., p. 152.

144 Jean-Claude Pinson, Hegel, le droil et le libéralisme, Paris, PUF, 1989, p. 6.

${ }^{445}$ D'Hondt, aLa personne et le droit abstrait selon Ilegelm, en Droit et liberté selon Hegel, Planty-Bonjout (ed.), op. cit. pp. 108-09.

3 Itting, aLa estructuras, op. cit., p. 91 .

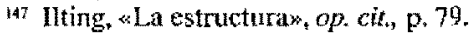

148 Pinson, Hegel, le droit et le liberralisme, op. cit, p. 212 . 
149 Mercier-Josa, Retour sur le jeune Marx, op. cit. p. 180.

1so Denis Rosenfield. Politica y libertad, op. cut., p. 293.

151 El término forma parte del vocabulario de Nietzsche: Consitteraciones intempestivas, I, 6 (Sämliche Werke, op. cit, bd 1, p. 191: wer einmal an der Hegelei... erkrankte, wird nie wieder ganz curients). La traducción por Sánchez Pascual de] pasaje dice: đJamás vuelve a curarse del todo nadie que haya estado enfermo de hegelianeria” (Madrid, Alianza, 1988, p. 81). Para el contexto presente sirve mejor el término whegelitiss, que utiliza Rufino Jimeno, traductor de Hans
Küng, La encamación de Dios. Introducción al pertsamiento de Hegel como prolegómenos para una cristologia futura (Barcelona, Herder, 1974), en cuya página 13 se traduce asi el mismo pasaje: «El que una vez estuvo enfermo de "hegelitis" jamás se cura del todo.*

*Hegelianeria» refleja muy bien en castellano el juicio de valor negativo de Nietzsche sobre Hegel $\longrightarrow$ de ahí el acierto de Sánchez Pascual-; «hegelitis» aludiría simplemcnte a una profunda pasión por Hegel, capaz. de producir trastornos pero sin implicar un juicio negativo respecto al agente que los produce. Sería nuestro saso. 